\title{
REDISEÑANDO EL SISTEMA DE PROTECCIÓN A LA INFANCIA EN CHILE* Entender el problema para proponer modelos de cuidado alternativos y ayudar a la reunificación familiar
}

\author{
Francisca de Iruarrizaga Tagle
}

\begin{abstract}
RESUMEN: Chile ha intentado avanzar hacia la desinstitucionalización de la primera infancia, pero la falta de alternativas validadas hace que los centros residenciales sigan siendo la principal solución para estos niños separados de sus padres debido a situaciones de abuso o negligencia. El objetivo de este análisis de política es abordar el problema de la internación con una propuesta de tres niveles: elaborar una mejor comprensión de los problemas para diseñar soluciones adaptadas a cada situación, crear modelos de cuidado alternativos como soluciones temporales y posibilitar una reunificación familiar permanente.
\end{abstract}

Palabras Clave: protección a la infancia, Sename, familias de acogida, desinstitucionalización.

RECIBIDO: julio 2015; ACEPTADO: octubre 2015.

Francisca de Iruarrizaga. Economista de la Pontificia Universidad Católica de Chile, Magíster en Economía mención en Políticas Públicas por la misma casa de estudios y Master in Public Administration in International Development, por la Harvard Kennedy School of Government. Consultora del Banco Mundial en el programa de Protección Social y Empleo. Profesor part-time de la Facultad de Economía de la Universidad Católica. Email: fdeiruarrizaga@gmail.com.

* La autora quiere agradecer los comentarios realizados por Julie Wilson y Michael Walton, profesores de Harvard Kennedy School of Government, así como los recibidos de los evaluadores anónimos de Estudios Públicos. 


\title{
REDESIGNING THE CHILEAN CHILD PROTECTION SYSTEM: UNDERSTANDING THE PROBLEM TO PROPOSE ALTERNATIVE CARE MODELS AND HELP FAMILY REUNIFICATION
}

\begin{abstract}
AвSTRACT: Chile has tried to move towards early childhood deinstitutionalization, but the lack of validated alternatives makes residences still be the main solution for children removed from their parents due to abuse or neglect. This policy analysis aims to address the problem of children's institutionalization with a three level proposal: to elaborate better understanding of the problems to design tailored solutions, create alternative care models as temporary placements and enable permanent family reunification.
\end{abstract}

Keywords: child welfare, Sename, deinstitutionalization, foster care.

RECEIVED: July 2015; ACCEPTED: October 2015.

\section{INTRODUCCIÓN}

E n 2014, la Presidenta Bachelet creó el Consejo Nacional de la Infancia, ${ }^{1}$ con la misión de diseñar una política nacional para la infancia y coordinar las diferentes organizaciones públicas que brindan servicios para la infancia. El Consejo entre sus mandatos tiene el de desinternar a los menores de ocho años, comenzando por los menores de tres. $^{2}$ Este artículo se centra en la reforma necesaria para llevar a cabo una desinternación exitosa y entrega recomendaciones de política para su implementación efectiva.

${ }^{1}$ El Consejo Nacional de la Infancia depende formalmente del ministerio Secretaría General de la Presidencia (Segpres) y está conformado por los ministros de Justicia, Trabajo, Salud, Educación, Desarrollo Social, Hacienda, Servicio Nacional de la Mujer y Consejo Nacional de la Cultura y las Artes. También cuenta con representantes de otros ministerios y servicios como invitados permanentes.

${ }^{2}$ La política de desinternación está definida para la primera infancia, la que en Chile, siguiendo los lineamientos de Unicef, se define desde la gestación hasta los ocho años de edad. 


\section{El problema}

Chile reconoce que los niños son titulares de derechos y que la primera infancia es un período clave de grandes oportunidades (y riesgos) para el desarrollo humano; por ende, invertir en la infancia es estratégico para el país (Informe del Consejo Asesor Presidencial para la Reforma de las Políticas de Infancia 2006). Una meta apropiada para el país sería que todos los niños tuvieran las mismas oportunidades de crecer y transformarse en ciudadanos productivos y respetuosos de la ley. Desafortunadamente, muchos niños no reciben la crianza y el apoyo de sus padres. Para enfrentar esta situación, Chile ha promulgado leyes y creado un sistema que permite identificar a estos niños y jóvenes, mejorar su situación familiar o separarlos de sus familias.

Al igual que en otros países, los niños que son alejados de sus padres debido a situaciones de abuso o negligencia generalmente son destinados a instituciones y no a otras familias, a pesar de que la ley establece que la internación es la última opción. Las alternativas familiares no están funcionando adecuadamente y es preciso corregir varias deficiencias del sistema para crear un servicio que promueva un desarrollo infantil saludable.

En este estudio se propone un rediseño del sistema de protección de la infancia teniendo como objetivo la recuperación del niño y su reintegración a la vida familiar. Para ello, se plantea una solución en tres niveles: primero, utilizar más información para diseñar soluciones a la medida; segundo, crear modelos alternativos de cuidado para responder a las necesidades específicas de cada niño en materia de destinos temporales; y tercero, implementar una red de intervenciones para resolver los problemas más profundos que afectan a esas familias, a fin de alcanzar una solución permanente a través de la reunificación familiar.

El enfoque utilizado consiste, en primer lugar, en identificar el problema; segundo, realizar un diagnóstico del problema en profundidad; tercero, diseñar soluciones de política factibles basadas en la teoría y la evidencia; cuatro, implementar y poner a prueba la solución; y quinto, redefinir la solución a través del monitoreo y aprendizaje permanente. ${ }^{3}$ Es una trayectoria circular en la cual se introducen nuevos datos

${ }^{3}$ Este enfoque se conoce como "diseño de política inteligente" y se utiliza para el análisis e implementación de políticas concibiéndolas como un desafío de diseño. Para mayor información, véase http://epod.cid.harvard.edu. 
y aprendizajes para mejorar el diseño de la política. Este artículo sólo abarca los tres primeros pasos y propone que el Sename siga incorporando los aprendizajes de su implementación en futuros rediseños. Se hace hincapié en la necesidad de contar con evidencia adecuada para una mejor identificación y diagnóstico del problema.

\section{El contexto}

De acuerdo con los índices de violencia interpersonal y homicidios, América Latina es la región más violenta del mundo. Comparado con otros países del continente, Chile tiene los índices más bajos en esta materia, incluida la violencia contra los niños. La tasa de homicidio de niños y adolescentes ( 0 a 19 años) es de 2 por cada 100 mil habitantes (Unicef 2014). Sin embargo, estos índices siguen siendo altos para el estándar mundial.

Según datos del Ministerio del Interior y Seguridad Pública (MISP), se registran aproximadamente 120 mil denuncias por violencia intrafamiliar al año, al tiempo que casi un tercio de las mujeres encuestadas de Chile declaran haber sido víctimas de violencia. Con respecto a los niños, el 70 por ciento declara haber sido objeto de violencia psicológica; el 52,8 por ciento, de violencia física leve; y el 25,4 por ciento, de violencia física severa (Fundación Paz Ciudadana 2013, basado en datos del MISP y Adimark GfK 2013). El 6,8 por ciento de los estudiantes de 11 a 17 años manifestaron haber sido objeto de negligencia o abandono por parte de sus tutores. Adicionalmente, el 7,3 por ciento declaró haber sufrido toqueteos sexuales o haber sido obligado a realizar actos sexuales, con mayor prevalencia en las mujeres (9,9 por ciento), y la agresión generalmente provino de un familiar cercano (MISP y Adimark GfK 2013). ${ }^{4}$

Unicef, según una encuesta autoadministrada a niños en escuelas, revela que el 71 por ciento de los infantes en Chile ha sufrido algún tipo de violencia y el 25,9 por ciento ha padecido violencia física severa. $\mathrm{Si}$ se compara con encuestas anteriores, el número de niños agredidos ha disminuido, pero las cifras siguen siendo alarmantes (Unicef 2012). ${ }^{5}$

${ }^{4}$ Esta encuesta fue realizada a una muestra representativa de estudiantes matriculados en escuelas urbanas.

${ }^{5}$ El tamaño de la muestra fue de 1.555 encuestados y abarcaba sólo a 7 de las 15 regiones del país. 
Sin embargo, se desconoce qué porcentaje de estas víctimas son acogidas por el Sename y esto podría ser un problema mucho más grave para Chile de lo que parece. Lo que sí se sabe es que la institución recibe, por lo general, a niños provenientes de hogares de bajos ingresos. Dado el impacto que tiene la pobreza en la capacidad de muchas familias para brindar un cuidado adecuado a sus hijos, no resulta sorprendente que los niños que viven en situación de pobreza sean remitidos a servicios de protección para la infancia con mayor frecuencia (Barbell y Freundlich 2001, 9).

Preguntas claves sobre la relación entre pobreza, maltrato infantil y la decisión de poner a los niños bajo tutela de terceros siguen sin respuesta. ¿Hasta qué punto la negligencia como factor de riesgo para los niños está determinada por la pobreza y no por una paternidad inadecuada? (Barbell y Freundlich 2001). Éste es un tema controvertido en Chile, y algunos casos de traslados de niños han sido denunciados como discriminatorios contra las familias pobres. Si bien es un tema de suma importancia, este artículo no se abocará a responder a estas preguntas, sino que se enfocará en la población que es actualmente atendida en los servicios de protección a la infancia.

\section{La relevancia del problema}

Los niños bajo protección estatal son un problema menor en términos de su magnitud al representar sólo el 0,3 por ciento de la población infantil de Chile. ${ }^{6}$ Sin embargo, constituyen un severo problema, un enorme desafío de política pública y un alto costo para el Estado. Si no se les entrega apoyos y servicios adecuados a los niños víctimas de maltratos y simplemente se les destina a instituciones que agudizarán el daño que padecen, no podrán crecer como adultos plenos. Este ciclo de daño tiene altas probabilidades de llevar a una transmisión intergeneracional de pobreza y disfuncionalidad que el país debe enfrentar.

La existencia de niños que no crecen adecuadamente para llevar una vida socialmente plena y productiva se transforma en un alto costo

${ }^{6}$ Según el Instituto Nacional de Estadísticas (INE), Chile tiene una población de 17.819.054 habitantes proyectada para 2014, de los cuales 4.732 .667 son menores de 18 años (27 por ciento) y 2.206.062, menores de ocho años, lo que equivale al 12 por ciento de la población. 
para el Estado, en la medida en que dependerán durante toda su existencia de programas asistenciales y tendrán una mayor probabilidad de padecer problemas mentales serios o de ser recluidos en instituciones penitenciarias. Por ejemplo, el último censo de personas que viven en situación de calle arrojó que el 25 por ciento de los indigentes en Chile habían vivido en un centro residencial durante su infancia (Ministerio Desarrollo Social 2012), lo que viene a reflejar cómo estos niños tienen una mayor probabilidad de ser indigentes durante su vida adulta.

En Chile no existe un seguimiento a los niños que pasan por centros residenciales que nos permita conocer su trayectoria futura y estudiar el efecto que tuvo en sus vidas la internación en distintas dimensiones. Sin embargo, existe un estudio que indica que, 12 meses después de abandonar el programa, el 8 por ciento de los niños que habían dejado de ser beneficiarios de los programas de protección al cumplir la edad reglamentaria habían ingresado al sistema de justicia juvenil. También muestra que factores como el ingreso temprano al programa, la deserción escolar, el consumo de drogas, la cantidad de veces que el niño había ingresado al sistema y el trabajo infantil se correlacionaban positivamente con el ingreso al sistema de justicia juvenil una vez que abandonaban el sistema de protección infantil (Álvarez 2013).

Considerando los múltiples efectos negativos que trae consigo el maltrato infantil, los costos económicos asociados a este fenómeno son elevados. Diversos estudios realizados en los Estados Unidos han demostrado que el maltrato infantil produce secuelas de por vida en el ámbito social, económico y de la salud, así como problemas de comportamiento y de salud mental. Trae consigo mayores riesgos de conductas delictuales, criminalidad adulta y comportamiento violento; mayor probabilidad de enfermedades crónicas; efectos duraderos o discapacidades por lesiones físicas; menor calidad de vida en términos de salud; y menores niveles de bienestar económico en la vida adulta (Fang et al. 2012). Valiéndose de un enfoque basado en la tasa de incidencia, Fang et al. (2012) estimaron que la carga económica de por vida asociada al maltrato infantil equivalía a 210.012 dólares por víctima de maltrato infantil no fatal en los Estados Unidos (en dólares de 2010). ${ }^{7}$

${ }^{7}$ Esta estimación incluye 32.648 dólares en costos de salud infantil, 10.530 dólares en costos médicos para adultos, 144.360 dólares en pérdidas en productividad, 7.728 dólares en costos de asistencia social a menores, 6.747 dólares en costos de justicia penal y 7.999 dólares en costos de educación especial. También estimaron en 1.272.900 dólares el costo por víctima de maltrato infantil fatal. 
Las consecuencias de largo plazo asociados con el abuso y la negligencia a niños hacen que la prevención de este flagelo sea una tarea prioritaria. Sin embargo, este artículo no abarca el tema de la prevención, sino que se centra en la recuperación de niños que han sido víctimas de abuso y negligencia.

\section{Estructura de este artículo}

Tras una breve introducción en la que se enuncia el problema y su relevancia, este artículo presenta, en la sección II, una serie de antecedentes que permiten comprender el sistema de protección a la infancia de Chile. En la sección III se ahonda en el problema, intentando identificar la población de análisis a través de una caracterización de los niños que están en el sistema, un análisis de los centros residenciales y de los programas de familias de acogida actuales, para luego establecer criterios para definir una buena atención. En la sección IV se analiza la desinternación y se procura explicar por qué es un problema según la evidencia internacional; asimismo, se constata la falta de datos para el caso de Chile. También se incluye un análisis de iniciativas previas de desinternación y se propone un mejor marco de referencia para esta reforma. Seguidamente, en la sección V se presentan tres propuestas que apuntan a lograr una mejor caracterización del problema, crear modelos alternativos de atención a los niños y brindar servicios para promover la reunificación familiar. Finalmente, en la sección VI se analiza la factibilidad de esta reforma en función de su idoneidad técnica, factibilidad administrativa y apoyo político. En el anexo se incluyen las referencias bibliográficas y la lista de personas entrevistadas para este artículo como parte del análisis cualitativo.

\section{HACIA UNA COMPRENSIÓN DEL SISTEMA DE PROTECCIÓN INTEGRAL DE LA INFANCIA EN CHILE}

\section{El Sename: la institución de protección de la infancia}

El Servicio Nacional de Menores (Sename) ${ }^{8}$ fue creado en 1979, bajo la supervisión del Ministerio de Justicia, para proteger los derechos de los niños y controlar y regular la adopción. Esta organización

${ }^{8}$ El objeto de este estudio es acotado y no pretende cubrir otros aspectos de este servicio o la necesidad de reformar su institución. 
incluye los servicios para los infractores de ley y para los menores de edad víctimas de abuso o negligencia. ${ }^{9}$ Este artículo se centrará en los servicios de protección de menores: los programas estatales de prevención y respuesta para los niños que han sido víctimas de violencia, abuso o negligencia.

Los programas del Sename son principalmente ejecutados a través de organismos colaboradores acreditados (OCA), sin fines de lucro, que participan en procesos de licitación ligados a proyectos y reciben subvenciones en función de los niños atendidos. El Sename supervisa la prestación de los servicios.

El Sename, en términos de protección a la infancia, atiende a aproximadamente 170 mil niños a través de programas y centros residenciales, de los cuales el 70 por ciento es objeto de intervenciones durante menos de un año, con una duración promedio de cuatro meses..$^{10} \mathrm{Al}$ final del año 2013, el Sename contaba con 80 mil niños y adolescentes activos en sus programas (Sename 2014).

El porcentaje de los niños de la red Sename que se encuentran viviendo en instituciones ha disminuido (Mide UC 2013). Mientras que en 1990 un 62 por ciento de los menores bajo el alero del Sename vivían en centros residenciales (Aldeas Infantiles SOS Internacional y Relaf 2010; Mide UC 2013), en 2013 ese porcentaje se había reducido a un 12,5 por ciento (Sename 2014).

Actualmente, la mayoría de los niños son beneficiarios de programas de diagnóstico ambulatorio (DAM), programas de intervención breve (PIB), servicios de la Oficina de Protección de Derechos (OPD) $\mathrm{u}$ otros programas mientras siguen viviendo con sus familias. ${ }^{11}$ Durante

\footnotetext{
${ }^{9}$ Al momento de editarse este artículo (enero de 2016), el Congreso está discutiendo un proyecto de ley que separa estos dos servicios. Elimina el Sename y crea el Servicio de Protección para la Infancia (dependiente del Ministerio de Desarrollo Social) y el Servicio de Responsabilidad Criminal Adolescente (bajo el alero del Ministerio de Justicia).

${ }^{10} \mathrm{Si}$ un menor participó en más de un programa durante un año o reingresó al servicio puede ser contado dos veces al momento de considerarse la cantidad total de servicios prestados. Esta información se basa en las estimaciones de la autora a partir de la base de datos del Sename con información para todos los niños atendidos por los Servicios de Protección durante 2013, solicitados a través del Servicio de Transparencia.

${ }^{11}$ El número de menores por tipo de programa puede consultarse en Sename (2014). En www.sename.cl, en la sección "Oferta de protección”, se encuentra una breve descripción de los programas.
} 
2013, sólo 13.265 niños estaban albergados en centros residenciales o programas de familias de acogida (Sename 2014).

La desinternación de los menores se funda en el derecho de vivir en familia, que tiene fuerza de ley desde que Chile firmó la Convención de Derechos del Niño (CDN) en 1990. Desde entonces, la idea ha sido reducir la internación masiva, sin eliminarla del todo, pero asegurándose de que constituya la última opción para los menores que no pueden desarrollarse en el seno de una familia (Unicef 2005).

\section{Marco regulatorio}

El marco regulatorio del Sistema de Protección Integral a la Infancia en Chile está determinado por:

- La Convención de los Derechos del Niño; ${ }^{12}$

- Decreto Ley n. ${ }^{\circ} 2465$, de 16 de enero de 1979, que crea el Servicio Nacional de Menores (modificando el existente Consejo Nacional de Menores) y establece las causas de protección a la infancia;

- La Ley n. ${ }^{\circ} 19.620$ del 5 de agosto de 1999, que regula la adopción;

- La Ley n. ${ }^{\circ} 19.968$, del 25 de agosto de 2004, que crea y regula los Tribunales de Familia;

- La Ley n. ${ }^{\circ} 20.032$, del 11 de julio de 2005, que establece el sistema de atención a la niñez y la adolescencia y las subvenciones para los proveedores privados de centros residenciales y programas de acogimiento (OCA).

En 2004, con la creación de los juzgados de familia, el sistema de protección de la infancia cambió su foco: se determinó que separar a un niño de su entorno familiar era la última opción y que requería una orden judicial. Empero, a pesar de que fue establecido como un recurso extremo, en la práctica no siempre se agotan todas las vías alternativas (Relaf et al. 2013).

El Gobierno está, al editarse este estudio, trabajando en el diseño de una nueva ley de garantías de derechos para la infancia a fin de responder a los requerimientos de la CDN de las Naciones Unidas, y alinear el marco regulatorio de Chile con la convención internacional.

12 Para mayor información sobre los derechos establecidos en la Convención sobre los Derechos del Niño, véase http://www.unicef.org/crc/files/Rights_overview.pdf. 


\section{Cómo opera el sistema}

La denuncia de casos de maltrato infantil o negligencia es obligatoria para los proveedores de atención a menores, funcionarios públicos y personal educativo y de salud. ${ }^{13}$ La denuncia puede ser formulada a través de la Oficina de Protección de Derechos (OPD), Carabineros de Chile, Policía de Investigaciones, el Instituto Médico Legal o directamente al Sename o a la Fiscalía.

\section{Diagrama 1: FUNCIONAMIENTO DEL SISTEMA}

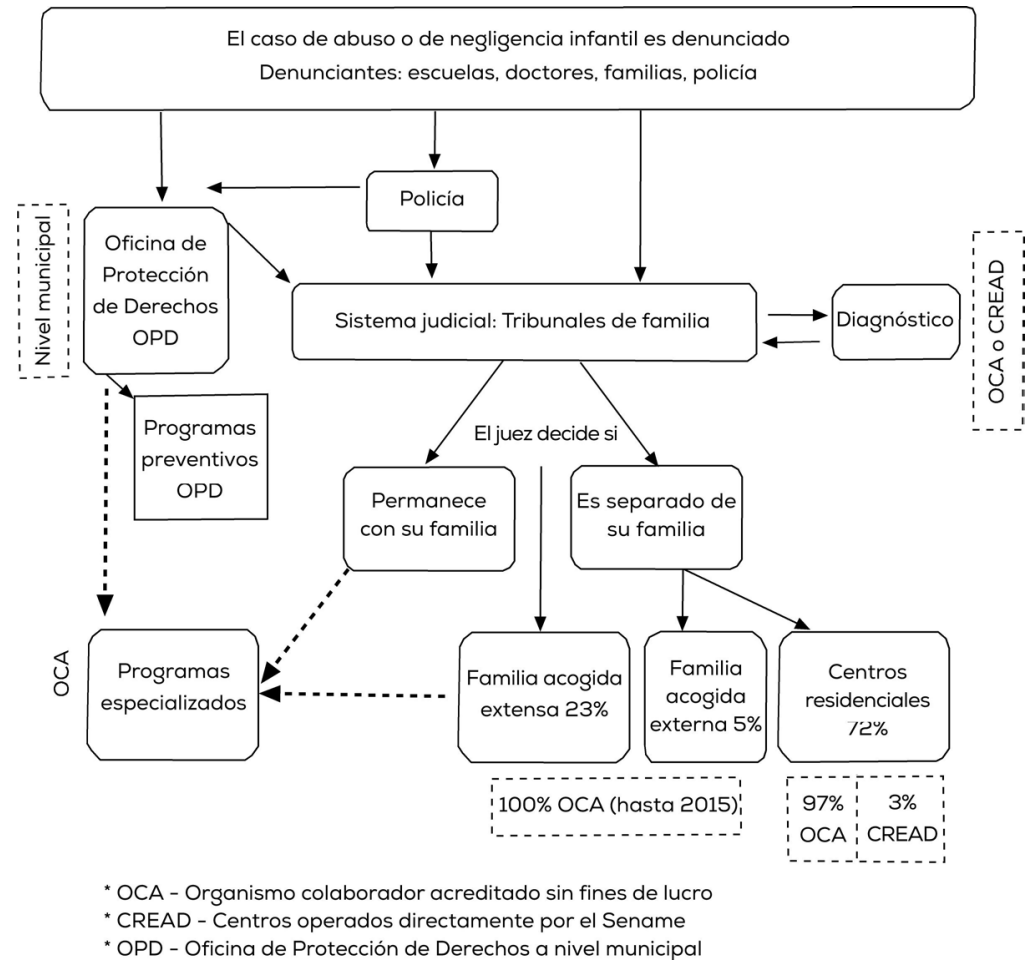

De ser necesario, los casos son remitidos directamente a los juzgados de familia; de lo contrario, la OPD debe hacer un seguimiento del caso y, si hay cupos disponibles, incorporar al menor a un programa ambulatorio. Si un caso es remitido a los juzgados de familia, el juez

${ }^{13}$ La Ley n. ${ }^{\circ} 19.968$, en su artículo 84, establece que las personas especificadas en el artículo 175 del Código Procesal Penal están obligadas a denunciar hechos que pudieren constituir violencia intrafamiliar. 
solicita un diagnóstico del menor y de su familia al Sename o a un organismo colaborador del Sename, y posteriormente decide si el menor debe ser removido de su hogar.

Si la decisión apunta a separar al menor de su hogar, el juez recibe información de parte del equipo técnico respecto de los posibles lugares de destino. Primero, se averigua si existe algún familiar que pudiera asumir la tutela del menor, pero si nadie puede o quiere hacerse cargo de su situación, éste es enviado a un centro residencial.

Si un familiar está dispuesto a asumir el cuidado del niño, el juez puede conferirle la tutela y, según el caso, realizar algún tipo de seguimiento hasta que se cierre la causa, remitirlo a algún programa de intervención ambulatoria o enviarlo a algún programa de familias de acogida que le brinde apoyo y supervise a la familia. ${ }^{14}$

\section{IDENTIFICACIÓN DEL PROBLEMA}

\section{1. ¿Quiénes son los niños bajo la tutela del Estado?}

En esta sección se pretende dilucidar el problema de la internación por la vía de comprender quiénes son los niños que forman parte del sistema. Lo primero a señalar es que para una adecuada identificación se requiere de mejor información. Desafortunadamente, no se dispone de datos sistemáticos respecto de las familias de estos menores y sus problemas. El Sename dispone de muy poca información del menor, pero los Juzgados de Familia tienen archivos más pormenorizados de cada caso, y otros ministerios cuentan con información individual que, con la debida autorización, es fácil de unir. Este punto será abordado más adelante en las recomendaciones de política. ${ }^{15}$

${ }^{14} \mathrm{Si}$ se diera esta última opción, la institución de acogida debe tener cupos disponibles; de lo contrario, el juez puede recurrir al artículo 80 bis de la Ley n. ${ }^{0} 19.968$ (Juzgados de Familia), que estipula que el juez puede ordenar el ingreso de un caso a un programa aunque no haya cupos disponibles.

15 Otras caracterizaciones de los menores bajo protección estatal también pueden hallarse en Martínez (2010) y Observa (2014). Ellos también recurren a la información proporcionada por la base de datos administrativa del Sename (Senainfo). Esta base de datos sirve para gestionar los pagos a cada OCA. Por ende, los datos almacenados no están orientados a caracterizar a los niños y no ayudan a identificar y comprender sus problemáticas. Por ejemplo, no existe una definición de pobreza y un menor es caracterizado como pobre según los criterios de la persona en el OCA que ingresa el caso. 


\subsection{Causal de ingreso}

Según datos del Sename, los menores ingresan a centros residenciales por varios motivos, definidos en más de 64 categorías. Los más comunes son negligencia, inhabilidad de los padres y diferentes tipos de maltrato. ${ }^{16}$ Pero las causales no son específicas y no arrojan luces sobre los problemas subyacentes en la familia.

La causal de ingreso principal es registrada por los OCA, en base al dictamen del juez. Una vez que el centro evalúa al menor pueden sumarse nuevas causales al expediente, pero no queda claro cómo se clasifican las causales de ingreso, por ejemplo, al distinguir entre negligencia e inhabilidad de los padres.

Cuál es la principal causa de ingreso varía según el tipo de programa. Para todos los niños que participan en programas de familias de acogida o que reciben atención en instituciones, la principal causal es haber sido víctimas de maltrato o abuso, haber ingresado para un diagnóstico o la incapacidad de sus padres para hacerse cargo de ellos (ver el gráfico 1). ${ }^{17}$

\section{Gráfico 1. CAUSAL DE INGRESO PARA MENORES DE TODAS LAS EDADES Y BAJO TUTELA ESTATAL}

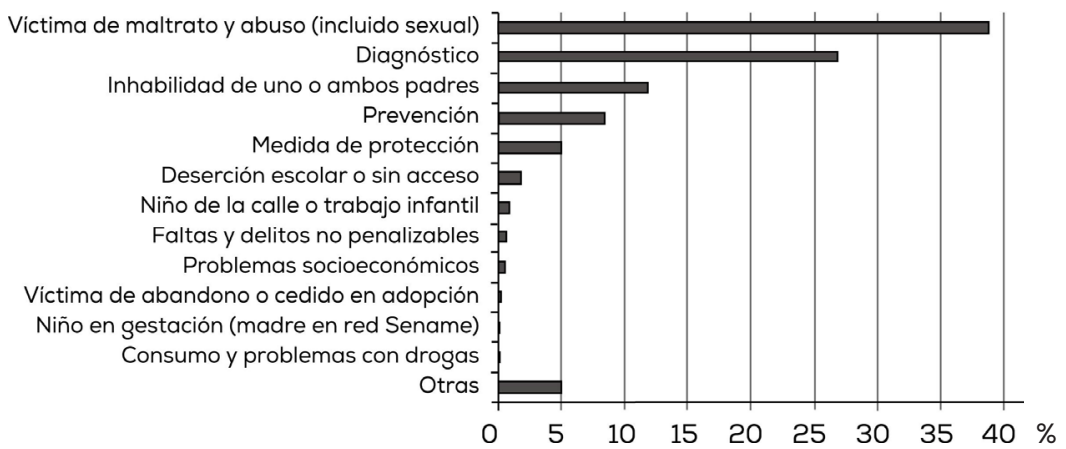

Fuente: Estimaciones de la autora a partir de datos de Sename (2015). Población: todos los niños bajo tutela estatal.

Para la población destinataria de la política de desinternación (menores de ocho años que viven en centros residenciales), las principales

${ }^{16}$ Estimaciones realizadas por la autora utilizando la base de datos de Senainfo 2014 de niños atendidos en centros residenciales, solicitados a través del Servicio de Transparencia.

${ }^{17}$ Como ya se dijo, la definición de cada categoría es vaga y la "inhabilidad parental" puede abarcar diferentes tipos de problemas. No resulta claro en qué medida ésta difiere de la negligencia. 
causales de ingreso son la negligencia, la inhabilidad de los progenitores o el peligro físico o moral del niño (véase el gráfico 2).

\section{Gráfico 2. CAUSAL DE INGRESO, NIÑOS DE 0-8 EN CENTROS RESIDENCIALES}

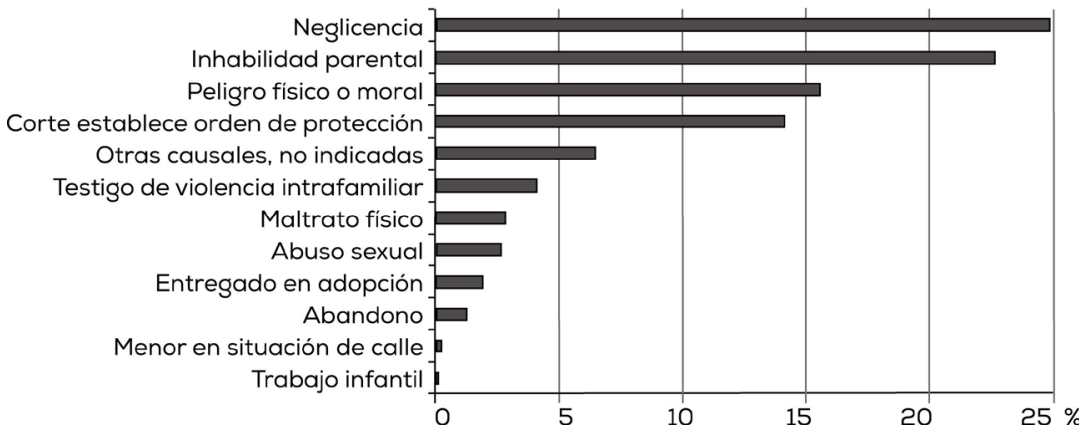

Fuente: Estimaciones de la autora en base a la información de Senainfo (2014). Población: niños de 0 a 8 años albergados en centros residenciales.

\subsection{Distribución por edad y género}

No existe una diferencia significativa en términos de género para los menores de ocho años que viven en instituciones: el 49 por ciento son mujeres y el 51 por ciento, varones. En términos etarios, se produce una mayor concentración en los de mayor edad, habiendo más niños entre cuatro y ocho años que de cero a cuatro (véase el gráfico 3).

Gráfico 3. NÚMERO DE MENORES EN CENTROS RESIDENCIALES, SEGÚN SU EDAD (EN MESES)

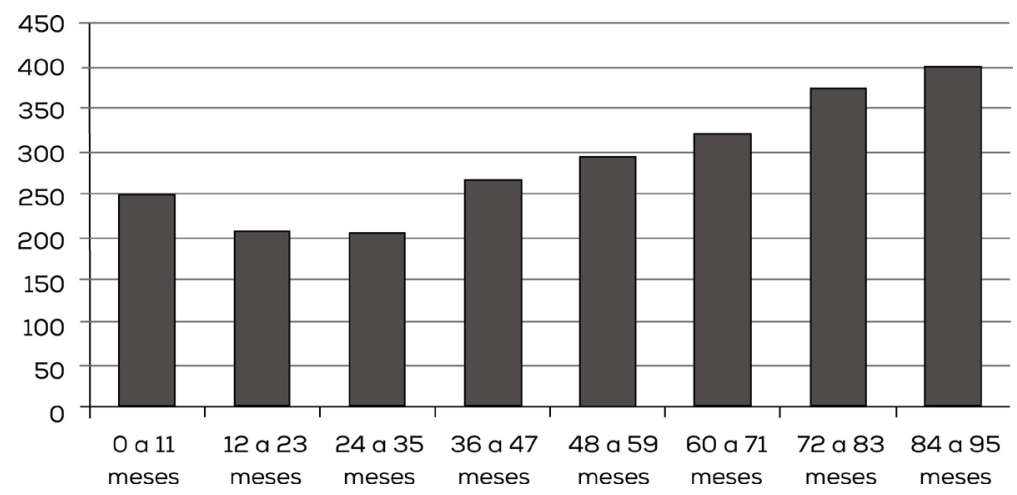

Fuente: Datos obtenidos del Consejo Nacional de la Infancia (2015). Población: niños de 0 a 8 años albergados en centros residenciales. 


\subsection{Tiempo de permanencia en el programa}

Para todos los niños bajo la tutela del Estado, cuando se comparan los centros residenciales con los programas de familias de acogida, la duración de la estadía no varía sustancialmente: ninguna de las dos alternativas pareciera ser efectivamente temporal. Una estadía prolongada es la norma en hogares de menores con discapacidad (véase el gráfico 4).

Gráfico 4. TIEMPO DE PERMANENCIA POR TIPO DE ATENCIÓN, TODAS LAS EDADES

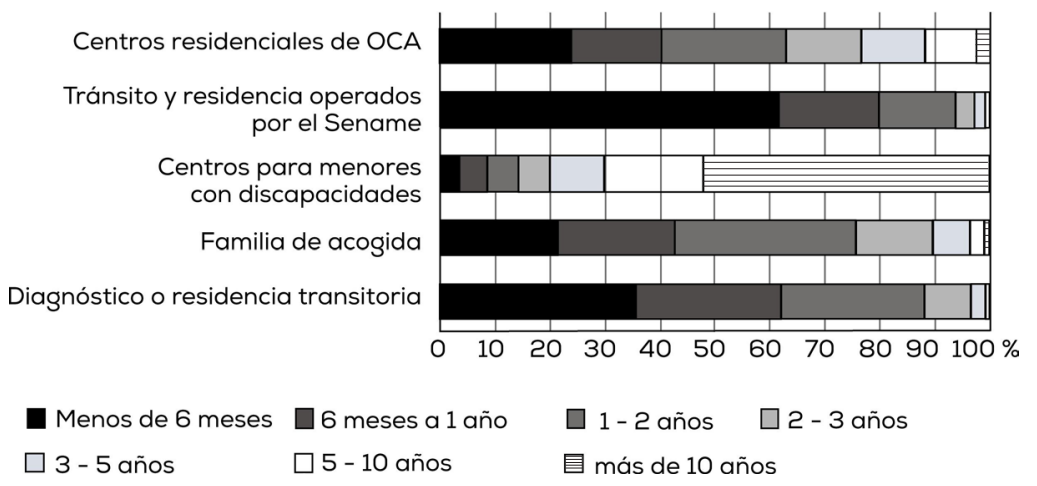

Fuente: Estimaciones de la autora a partir de información obtenida en Sename (2015). Población: todos los niños bajo tutela estatal.

Gráfico 5. MESES EN CENTROS RESIDENCIALES, SEGÚN EDAD DEL MENOR

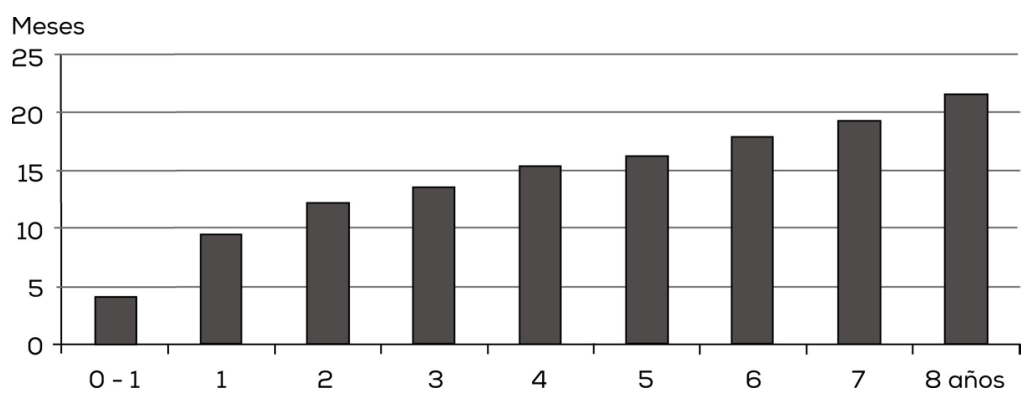

Fuente: Estimaciones de la autora a partir de información obtenida en Senainfo (2014). Población: niños de 0 a 8 años albergados en centros residenciales.

Los niños menores de ocho años han permanecido en promedio menos de dos años en los centros residenciales. El número promedio de 
meses de permanencia representa una proporción más alta de su vida en el caso de los más pequeños.

\subsection{Discapacidades o problemas de salud mental}

Entre los menores atendidos en centros residenciales, el 15 por ciento tiene discapacidades o patologías neuropsiquiátricas y el 6 por ciento sufre de enfermedades crónicas, tales como parálisis cerebral, epilepsia, desórdenes psiquiátricos, entre otras (Sename 2015). No está claro si esta información es exacta y completa, y no existen datos referidos a otros problemas comunes para los niños atendidos en centros residenciales.

Los problemas de salud y el nivel de desarrollo de muchos niños atendidos en centros residenciales tienen fuertes implicancias. Su carácter y severidad plantean serios desafíos en relación con los servicios brindados, la planificación de las estadías y el apoyo hacia los menores y sus familias (Barbell y Freundlich 2001).

\subsection{Egreso}

Según Sename (2015), menos del 50 por ciento de los menores que egresan han cumplido con los objetivos de la intervención. ${ }^{18}$ En cuanto a sus pasos futuros, el 82 por ciento vuelve a sus familias de origen, el 11 por ciento es derivado a otros programas del Sename y aproximadamente el 2 por ciento es entregado a familias sustitutas o adoptivas.

\subsection{Otros aspectos relevantes}

Un análisis más profundo de una muestra acotada de niños en programas de familias de acogida revela, según lo expresado por los cuidadores, que el 60 por ciento de las madres biológicas consumía drogas y el 53 por ciento tenía problemas de consumo de alcohol; en cuanto a los

${ }^{18}$ Este análisis es realizado sobre el universo de todos los menores que egresaron de los programas de acogimiento y centros residenciales de los diferentes OCA que operan con el Sename. 
padres, el 46 por ciento consumía drogas y el 44 por ciento tenía problemas de consumo de alcohol (Zavala y Jiménez 2014). ${ }^{19}$

En términos de la edad y de la cantidad de períodos de internación, el 60 por ciento de los niños que permanecían en centros residenciales ingresaron antes de cumplir cinco años y el 53 por ciento de los niños en centros residenciales o programas de acogimiento han ingresado al sistema más de cinco veces (Observa 2014). ${ }^{20}$ No hay información respecto de dónde se encuentran ni qué sucede entre su egreso y reingreso, pero el 80 por ciento de los niños que ingresaron a centros residenciales no estaban bajo la custodia de su familia de origen (Observa 2014).

En términos de quién solicita la admisión de un menor, los "otros programas del Sename" presentaron la mayoría de las solicitudes $(30,5 \%)$, seguidos por la policía $(11,8 \%)$ y los servicios de salud $(10,3 \%)$. Esto podría indicar que se prueban otras instancias y programas para niños antes de institucionalizar al menor, pero que éstos no logran evitar la internación (Sename 2015). No hay información disponible respecto del impacto que tienen estos programas, sus objetivos específicos ni cuán efectivos son.

\section{Formas de atención para niños bajo tutela estatal: centros residenciales y programa de familias de acogida}

\subsection{Centros residenciales}

Existen aproximadamente 300 centros residenciales que atienden a más de 15 mil niños al año. El 97 por ciento de estos centros son administrados por distintas ONG, y sólo diez de ellos son manejados directamente por el Sename - los Centros de Reparación Especializada de Administración Directa (CREAD) - , donde se reciben casos complejos y menores en tránsito mientras se les encuentra lugar.

${ }^{19}$ El estudio utiliza una muestra de 158 familias de acogida de la Región Metropolitana de una lista de familias proporcionada por diferentes OCA que trabajan con familias de acogida. De esa muestra, 105 correspondían a familias extensas y 53, a familias externas. El estudio no especifica cómo se seleccionaron a las familias.

${ }^{20}$ No existen estudios de seguimiento sobre a donde van los menores cuando egresan y si el reingreso obedece a las mismas causales de ingresos anteriores. 
En cuanto a las ONG que administran estos centros, existe una alta concentración de grandes instituciones que operan la mayoría de los programas. Esto no es necesariamente negativo, pero es relevante para comprender cómo funciona el sistema. En 2011, los OCA que operaban más de cinco proyectos representaban el 21 por ciento de las organizaciones que colaboraban con el Sename y gestionaban el 75 por ciento de los proyectos. Los OCA pequeños, que manejan sólo un programa, representan el 42 por ciento de las organizaciones y operan únicamente el 9 por ciento de los proyectos del Sename. En promedio, menos de dos OCA participan en cada proceso de licitación. Esto plantea la duda de si hay competencia entre estos organismos y si existen incentivos para brindar una mejor atención (Focus 2013).

En cuanto al tamaño, algunos centros albergan más de 90 menores, mientras otros son más pequeños o están organizados en casas pequeñas para preservar un "esquema de familia". El Sename promueve que alberguen un máximo de 20 niños por hogar, pero ese estándar es costoso y no siempre se cumple.

El Sename propone que los OCA adopten modelos personalizados de atención. Sin embargo, los cuidadores hacen turnos de acuerdo con horarios de trabajo y muchas veces se producen altas tasas de rotación, a pesar de que esto varía dependiendo de la organización (Chía et al. 2014). El Sename supervisa los centros residenciales y efectúa visitas mensuales, pero la información recolectada en las visitas no es sistematizada, por lo que no es posible analizar las características o los resultados de los OCA.

Los centros residenciales cubren las necesidades básicas de los niños, se aseguran de que asistan a la escuela y procuran interactuar con la familia de origen de los niños para promover la reunificación, pero algunos carecen de las herramientas especializadas y del personal adecuado para llevar a cabo esta tarea.

Estas instituciones están, por lo general, subfinanciadas en la medida en que los aportes del Sename no logran cubrir los costos de cuidar a un menor e interactuar con la familia (Focus 2011). ${ }^{21}$ En los últimos tres años, el 60 por ciento de los procesos de licitación promovidos por

${ }^{21}$ Según las entrevistas con algunas ONG, éstas reunieron fondos de privados que cubrieron, en algunos casos, aproximadamente el 60 o 70 por ciento de sus costos operacionales. 
el Sename para la gestión de los centros han sido declarados desiertos, lo que puede deberse a un bajo financiamiento (Focus 2013).

En los requerimientos técnicos para las licitaciones, el Sename establece estándares de calidad mínimos para los centros que son muy exigentes, que incluyen demasiados aspectos sin establecer prioridades y que no están definidos de manera medible. ${ }^{22}$

\subsection{Programas de familias de acogida}

Los programas de familias de acogida son de larga data en el país, pero han cambiado a lo largo del tiempo debido a las transformaciones culturales y socioeconómicas y a las nuevas regulaciones.

Antes no estaban regulados y consistían en una cuidadora que atendía a otros menores además de los suyos, usualmente en grupos grandes. En 2005, la Ley n. ${ }^{\circ} 20.032$, que define los aportes económicos a los OCA, estableció un nuevo énfasis técnico para los programas de acogimiento.

Hoy estos programas brindan asistencia y protección a niños que han sido privados de atención parental porque sus derechos han sido vulnerados. Estos menores son incorporados, a través de una orden judicial, en un grupo familiar alternativo como una solución temporal (Relaf et al. 2013).

Existen 47 programas de familias de acogida en 14 de las 15 regiones del país, con 3.374 derivaciones, de las cuales el 77 por ciento corresponde a familias extensas, es decir, que son familia consanguínea del niño (Relaf et al. 2013). Según los datos del Sename para el 2014, sólo el 5 por ciento de los niños bajo tutela estatal vive con una familia de acogida externa (que no tiene relación con el niño). Esto significa que aproximadamente 700 niños en todo el país reciben esta solución. En los Estados Unidos, el 47 por ciento de los niños bajo tutela estatal viven con familias de acogida externas (Children's Bureau 2013).

La selección de las familias de acogida es realizada por el juez en conjunto con un "proceso de validación" de los OCA respecto de quién

${ }^{22}$ Entre los múltiples aspectos, se incluye una atención personalizada, asegurar la privacidad, un máximo de tres niños por habitación y considerar la opinión del menor para la decoración del dormitorio. 
en la familia puede recibir al menor. El proceso de preselección, en caso de ser implementado, no es sistemático.

En lo que respecta a las familias de acogida externas o no biológicas, no existe un proceso formal de reclutamiento y el Sename no participa activamente en campañas de reclutamiento o de concientización. La responsabilidad pareciera recaer en los OCA, los cuales, en entrevistas para este trabajo, revelaron que no disponen de recursos suficientes para realizar esta tarea y los que intentaron reclutar vía campañas publicitarias no tuvieron mucho éxito.

Estos programas que trabajan con familias de acogida reciben un aporte económico de 90 a 130 mil pesos, dependiendo del tipo de programa, y al menos la mitad de ese monto debe ser transferido a la familia de acogida o a la familia de origen, si fuera necesario para el proceso de reunificación. El resto es destinado a los gastos relacionados con los servicios, administración y personal de las ONG que trabajan con los menores y con ambas familias. Existe un amplio debate entre los expertos respecto del monto que debieran recibir las familias de acogida y éste es un aspecto que debiera ser revisado al momento de diseñar un nuevo programa. Los programas de acogimiento que han sido exitosos en otros países entregan a las familias un monto que permite compensar el costo de tener a un miembro de la familia cuidando al niño en lugar de trabajar. ${ }^{23}$

Las evaluaciones de este programa revelaron que un número significativo de las familias de acogida padecían las mismas problemáticas que la familia de origen y no existían intervenciones para ayudar al menor a recuperarse del daño padecido (Martínez 2011; Sename 2011).

Zavala y Jiménez (2014) estudiaron una muestra de 138 menores en familias de acogida en la Región Metropolitana y concluyeron que el programa de acogimiento era una medida de protección adecuada y que las familias estaban asumiendo su rol de manera satisfactoria. Sin embargo, el estudio también reveló que casi la mitad de los menores habían tenido otros destinos previos a la familia de acogida actual y que las familias no recibían ninguna ayuda del programa o de otra entidad. Recomendaron que para asegurar un mayor bienestar de los menores se

${ }^{23}$ Programas exitosos, como el Proyecto de Intervención Temprana de Bucarest, entregaban un monto equivalente al salario medio, según información obtenida en la entrevista con el médico Charles Nelson, el 27 de octubre de 2014. 
duplicara el personal y se les ofreciera a los padres de acogida programas para mejorar sus capacidades parentales.

En 2013, el Sename reunió información de los implementadores de los programas de acogimiento y constató que sólo el 50 por ciento de los padres de acogida habían sido evaluados en sus capacidades parentales. En la mayoría de los casos, únicamente habían sido objeto de una evaluación social ( 80 por ciento) y una evaluación psicológica a través de exámenes que no distinguían su capacidad de asumir los cuidados de un menor. En sus recomendaciones planteó la necesidad de que los programas establecieran requerimientos y un proceso de selección para todas las familias de acogida, incluidos los parientes escogidos por los Tribunales de Familia (Sename 2013a). ${ }^{24}$

Un estudio cualitativo en el que se entrevistó a una muestra representativa de niños en las tres principales regiones del país reveló que, en la mayoría de los aspectos, las familias externas recibieron una mayor valoración que las familias extensas (características del hogar, atención emocional, privacidad, participación en la familia, salud, calidad de la relación). Las familias extensas sólo presentaban una mayor valoración ( 69 por ciento contra 49 por ciento) en cuanto a mantener una relación con la familia de origen del menor. Esto puede deberse a que, por definición, los niños en las familias extensas están más cercanos a sus familias originales; en algunos casos, pueden incluso permanecer en el mismo hogar. También puede deberse a que los menores son destinados a familias externas cuando sus familias extensas no pueden hacerse cargo de ellos, lo que indica una mayor disfunción familiar para aquellos que viven con familias externas (Sename 2013b).

\subsection{Productos y resultados de estas formas de atención}

El Sename cuenta con datos sobre los niños incorporados a cada programa, pero carece de información sobre los resultados. Existen algunas evaluaciones de los programas, pero en su mayoría se trata de estudios cualitativos realizados a partir de muestras pequeñas y que no miden impacto.

24 También constataron que había niños que vivían en programas de acogimiento dentro del mismo hogar que sus padres, de los cuales habían sido supuestamente separados. Adicionalmente, encontraron hasta nueve niños viviendo juntos, cuando la norma establece un máximo de cinco. 
Tres indicadores de desempeño utiliza el Sename: egreso exitoso, duración de la atención y no reingreso. La información sobre egresos exitosos es inútil en términos de análisis, dado que es entregada por cada organización y no tiene métricas estandarizadas (Focus 2013).

En cuanto a la duración, la atención en centros residenciales y programas de acogimiento exceden el tiempo estipulado, con niños que permanecen tres años en promedio, cuando la norma establece que deberían ser dos. ${ }^{25}$

Los resultados relativos al no reingreso varían según los diferentes modelos de atención: para los centros residenciales equivale al 63 por ciento y para los programas de familias de acogida, al 75 por ciento. Los resultados son más preocupantes tratándose de hogares de lactantes, con valores que bordean el 40 por ciento (Focus 2013).

\subsection{Estableciendo criterios: ¿qué implica un programa de familias de acogida de calidad?}

Las familias de acogida deberían satisfacer las necesidades básicas del menor y brindar un entorno seguro para su desarrollo sano, protegiéndolo del abuso y de la negligencia, brindándole estabilidad y proporcionando los servicios adecuados para responder a sus necesidades. También deben tener un foco familiar y brindar un servicio para toda la familia, y no sólo para el menor o para los padres biológicos (Barbell y Freundlich 2001).

A pesar de que los estándares de seguridad y sanidad son importantes, no garantizan de por sí un servicio de calidad. La gama completa de indicadores de calidad es muy amplia y puede variar entre familias de acogida externas y extensas. Para los cuidadores que son parte de la familia, puede que no sea necesario cumplir con ciertos requerimientos que pueden resultar difíciles para una familia de menos recursos (Berrick y Shlonsky 2001).

Los niños requieren un cierto grado de cuidado físico, alimentación y estimulación para alcanzar niveles normales de desarrollo y transformarse en adultos funcionales. Los menores que han sido maltratados pueden requerir apoyo adicional, pero son pocos los estudios empíricos

${ }^{25}$ En el caso de los menores de ocho años, el tiempo promedio de estadía es de menos de dos años. 
que cuantifican cuánta atención se necesita o cómo medir la calidad. Una mera elaboración de una lista de indicadores de calidad no basta si los cuidadores no crean entornos de calidad. La seguridad del menor, el apoyo para su desarrollo y necesidades especiales, así como la presencia de un cuidador cercano y estable son esenciales para una atención de calidad (Berrick y Shlonsky 2001).

Las bases técnicas de las licitaciones de los programas de familias de acogida establecen los requerimientos para los OCA que ejecutan dichos programas y para las familias con las que trabajan (Sename 2011). Sin embargo, no definen mecanismos claros para asegurar su cumplimiento ni un sistema de monitoreo.

\section{LA REFORMA GUBERNAMENTAL: EL MANDATO DE DESINTERNACIÓN}

\section{1. ¿Por qué la institucionalización es un problema?26}

Lo que sucede durante la primera infancia tiene implicancias para el resto de la vida. Como lo muestran las investigaciones sobre la biología del estrés, una adversidad de gran magnitud, como la pobreza extrema, el abuso o la negligencia, puede debilitar el desarrollo de la arquitectura cerebral y poner el sistema de respuesta corporal en un estado de alerta máxima, y éste puede producir daños acumulativos en la salud física y mental de un individuo (National Scientific Council on the Developing Child 2010; Shonkoff y Gardner 2012).

Varios estudios indican que una mayor acumulación de experiencias adversas durante la infancia se traduce en compartimientos sexuales riesgosos y acrecienta la probabilidad de transformarse en fumador o bebedor compulsivo, de ir a la cárcel, de sufrir obesidad mórbida, de tener magros resultados en materia de educación y empleo o de verse involucrado en actos de violencia (Baglivio et al. 2014).

Los jóvenes que viven en instituciones tienen más probabilidad de padecer mala salud y crecimiento físico deficiente, deterioro en su

${ }^{26}$ Esta sección fue preparada junto con Eugenia González para el curso "Movilizar la ciencia del desarrollo de la primera infancia para impulsar la innovación en las políticas y las prácticas", dictado por el profesor Jack Shonkoff, otoño de 2014, Harvard Graduate School of Education. 
desarrollo cerebral, retrasos en su desarrollo y desórdenes en su apego emocional. A su vez, estos niños tienen, en promedio, capacidades intelectuales, sociales y conductuales reducidas, si se las compara con aquellos que han crecido en el seno de una familia (Browne 2009).

Los niños bajo tutela estatal suelen tener una necesidad especial de cuidados sensibles y nutritivos, ya que muy probablemente provienen de situaciones de pobreza, abuso, negligencia u otras adversidades. Las disrupciones en su atención durante su custodia estatal pueden agravar los efectos del abuso y la negligencia (Dozier et al. 2002). Los lactantes son especialmente vulnerables debido a la interrupción de sus relaciones durante una fase crítica de su desarrollo (Cohen 2009).

Amplia evidencia indica que criar lactantes y menores en instituciones en las cuales se les niega el acceso y la exposición a entornos donde puedan recibir cuidados sensibles, receptivos, y tener interacción grupal y social se traduce en carencias y retrasos significativos. Estas carencias abarcan desde habilidades cognitivas básicas, problemas de lenguaje, coeficiente intelectual bajo, hasta problemas en las relaciones sociales, afectividad indiscriminada y comportamientos sociales que en algunos casos se asemejan al autismo. Los retrasos afectan el crecimiento físico y el desarrollo del lenguaje (Nelson et al. 2014).

Estudios científicos han demostrado también que cultivar relaciones estables, receptivas y nutritivas en los primeros años de vida puede prevenir o incluso revertir los efectos dañinos del estrés experimentado durante la primera infancia, con beneficios duraderos en términos de aprendizaje, comportamiento y salud para el resto de la vida (National Scientific Council on the Developing Child 2012).

Las familias de acogida pueden ser el espacio propicio para cultivar esas relaciones. Los datos indican que una atención de alta calidad puede servir para remediar de manera parcial carencias tempranas (Dozier et al. 2002). A pesar de que los infantes en el sistema de protección social son especialmente vulnerables ante posibles resultados negativos, una atención efectiva en familias de acogida puede prevenir daños futuros en los niños, ayudarlos a recuperarse del daño padecido y mejorar sus posibilidades de reinserción en la sociedad (Cohen 2009).

Sin embargo, es preciso establecer una salvedad: la atención en familias de acogida por sí sola no garantiza una atención de calidad. Tiene el potencial para brindar el cuidado nutritivo y sensible que en 
un centro residencial es más difícil entregar, pero éste debe ser implementado de manera adecuada para cumplir su función. Un programa de mala calidad en el cual los niños son trasladados de hogar en hogar puede ser tanto o más dañino que la internación (Cohen 2009).

\section{Implicancias de la evidencia para el caso chileno}

La idea de que los centros residenciales no son un buen lugar para el desarrollo de un niño se basa en estudios internacionales (especialmente aquéllos realizados en Rumania, presentados en Nelson et al. 2014) y ha sido promovida en Chile por la Unicef y por la Red Latinoamericana de Acogimiento Familiar (Relaf et al. 2013). En 2005, el gobierno de Chile suscribió el mandato de Unicef que establecía que los niños menores de tres años no debían ser llevados a instituciones. Se determinó que la atención en familias de acogida era la mejor alternativa para criar niños que hubieran sido separados de sus familias. En 2011, los programas de familias de acogida fueron reforzados como opción prioritaria, pero los esfuerzos para incrementar su cobertura fracasaron y los centros residenciales siguieron siendo la principal alternativa.

A pesar de que los centros residenciales en Chile pueden diferir de aquellos analizados en estudios internacionales, características como la atención grupal y la falta de un adulto significativo para desarrollar apego pueden estar presentes en las instituciones chilenas. La evidencia proveniente de la neurociencia y de la primera infancia es consistente en cuanto a que las instituciones no son adecuadas para el desarrollo de un niño.

Sin embargo, esta evidencia no indica que la atención en familias de acogida sea siempre mejor que la atención grupal. A pesar de que las familias de acogida constituyen un entorno más propicio para el desarrollo infantil que los centros residenciales, en la práctica el resultado depende de las características específicas del lugar. Hay un continuo de opciones desde la atención de calidad en familias de acogida hasta los centros residenciales masivos de baja calidad. En los extremos es evidente cuál es la mejor opción, pero resulta menos claro al comparar centros residenciales de alta calidad con programas de acogimiento de baja calidad. 
Existe un consenso de que en Chile tanto los centros residenciales como los programas de familias de acogida carecen de suficientes recursos para brindar un servicio adecuado o contratar personal calificado, y por lo tanto no están siendo capaces de producir los resultados esperados. Pero existe también una amplia diversidad en la forma en que los centros residenciales implementan sus programas, y es probable que algunos estén realizando una mejor labor en cuanto a brindar relaciones estables, receptivas y nutritivas que el actual programa de familias de acogida.

A los niños en centros residenciales y en familias de acogida no se les hace seguimiento y, como ya se explicó en la sección anterior, sólo se miden tres variables de resultados a nivel agregado. De acuerdo con esos datos, no hay diferencia en la duración de la estadía entre los dos programas y el egreso sin reingreso funciona mejor en el caso de las familias de acogida (Focus 2013).

Sin embargo, los resultados levemente mejores de los programas de acogimiento se complementan con el hecho de que, en promedio, el costo de un niño en una familia de acogida (FAE) es 44 por ciento más bajo que en un centro residencial: 118 mil pesos por niño al mes versus 157 mil (Focus 2013).

No existe información suficiente para evaluar la calidad del servicio o si existe reinserción social del menor. No hay información sobre el número de niños por cuidador, número de niños por hogar, tasas de rotación, grado de personalización de la atención, etcétera. No es posible demostrar que los centros residenciales son peores (o no) que los programas de familias de acogida para el desarrollo infantil, ya que no hay datos disponibles sobre resultados que permitan establecer mediciones, comparaciones o evaluaciones. Ese análisis es clave y debiera ser realizado antes de emprender cualquier reforma.

En Chile, los programas de familias de acogida no son percibidos como una alternativa legítima a los centros residenciales. Los OCA y los jueces entrevistados no estaban convencidos de que las familias externas fueran la solución a la internación, porque el Sename carece de la capacidad y de los recursos necesarios para monitorear a esas familias, y es un riesgo remitir niños sin una adecuada supervisión. Actualmente, existe más confianza en los centros residenciales, donde es más fácil supervisar y controlar (Relaf et al. 2013). 
Por ello, la reforma tiene que comenzar por diseñar una atención efectiva en las familias de acogida, con el objetivo de medir y comunicar su efectividad antes de optar por el cierre de los centros residenciales. En cuanto a esta opción, se debería comenzar por aquellos que tienen los peores resultados.

Un segundo paso al momento de decidir entre estas dos políticas —atención en centros residenciales o en familias de acogida- debería ser determinar cuál es la solución con mejor relación entre costo y efectividad; en otras palabras, cuál produce los mejores resultados a un menor costo. Para ese análisis se requieren datos relacionados con los resultados y los costos, pero, como ya se señaló, no hay datos sobre los resultados.

La evidencia de Focus (2011) sugiere que los programas de acogimiento tienen costos operacionales más bajos que los centros residenciales, principalmente porque las familias asumen el "costo de vida". Esto podría implicar que las familias de acogida son más costo-eficientes. Sin embargo, los implementadores de estos programas disienten, arguyendo que los programas están subfinanciados y carecen de los recursos necesarios para trabajar con las familias.

\section{Estudio de caso:}

\section{Un centro residencial que brinda una buena atención a lactantes}

La corporación de desarrollo Grada alberga a aproximadamente 40 infantes menores de dos años, con una proporción de cinco niños por cuidador. Satisface las necesidades básicas del menor y procura brindar un cuidado nutritivo y la estimulación necesaria para su adecuado desarrollo. La subvención estatal sólo alcanza para cubrir la mitad de los costos y para el diferencial recurre a donantes privados. Un alto porcentaje de los recién nacidos provienen de madres que consumieron drogas durante su embarazo. Esto se traduce en lactantes con problemas físicos, respiratorios y necesidades especiales, que son atendidos por un equipo de terapeutas físicos y un médico que visita semanalmente el centro. El hogar trabaja con las familias de origen y busca el mejor destino permanente para el menor. Sus integrantes argumentan que, dadas las necesidades especiales de estos menores, ponerlos bajo el cuidado de familiares no es la solución adecuada y que cualquier familia de acogida no es siempre la mejor alternativa a un centro residencial. 


\section{No es algo nuevo: iniciativas previas de desinternación}

La desinternación no es una política nueva en Chile y se pueden extraer lecciones de experiencias pasadas.

El fallido caso de la desinternación masiva de los niños que vivía en Ciudad del Niño (ver recuadro) es considerado un proceso que el país no

\section{Un caso previo de desinternación en Chile: Ciudad del Niño}

En 2003, después de 60 años de funcionamiento como centro residencial en San Miguel, Santiago, y respondiendo a las nuevas directrices de la Convención de Derechos del Niño, se procedió al cierre de Ciudad del Niño. El proceso masivo de desinternar a 315 menores consistió en devolverlos a su familia de origen cuando era posible o, en su defecto, trasladarlos a centros residenciales reconvertidos. Este proceso entraba en conflicto con la lógica imperante de internación de largo plazo (63 por ciento había estado albergado por más de tres años; algunos hasta doce años), al tiempo que no se contaba con una experiencia previa de desinternación y no se había realizado un trabajo previo con las familias.

Se definieron diferentes procesos de desinternación en función de la severidad del abuso o del maltrato y de la relación que el menor tenía con su familia, y se definieron procesos de hasta cinco años. Pero en la práctica, todo se materializó en un año.

Cuando se realizó el estudio de seguimiento no se pudo encontrar a un tercio de los menores; otro tercio había sido reinsertado en centros residenciales y el tercio restante vivía con sus familias. Los casos exitosos correspondían a menores con internaciones breves, niños que tenían relación con sus familias y familias que habían solicitado previamente recuperar a su hijo.

El proceso ha sido cuestionado por su masividad y celeridad, la ausencia de interacción con las familias y de una estrategia de seguimiento para acompañar los casos. No hubo un trabajo para conectarlos con otras redes, como el sistema escolar, el sistema de salud o la oficina local de protección de derechos.

quiere repetir. Entre las lecciones aprendidas figura la necesidad de trabajar con las familias de origen, dar una solución individualizada que dependa de la situación del niño, y realizar un proceso de seguimiento. ${ }^{27}$

${ }^{27}$ El caso se basa en el análisis realizado por Unicef (2005). El cierre de Ciudad del Niño y los aprendizajes para futuras desinstitucionalizaciones también son analizados en Muñoz et al. (2004). 
En 2013, se implementó un nuevo programa piloto de desinternación, con el propósito de generar una propuesta para el país. Éste consistía en desinternar a doce lactantes de un centro residencial y llevarlos a familias de acogida, reconvertir el centro residencial y capacitar a todos los actores implicados. Pero sólo pudieron desinternar siete niños (Relaf et al. 2013).

Esta experiencia piloto fue útil para informar respecto de los nodos claves entre los diferentes actores implicados, pero no proporcionó pautas útiles para el proceso de desinternación a nivel nacional. Dado que el piloto consistió en sólo un centro residencial y un programa de familias de acogida, no sirvió para entender cómo se debería implementar un proceso de desinternación a nivel nacional.

La Fundación Rodelillo también vivió una experiencia de desinternación, descrita en Unicef (2002). Intentaron establecer una red de apoyo para las familias. Entre las lecciones aprendidas está la necesidad de diseñar procesos de mediano a largo plazo, con más recursos y profesionales, y un trabajo coordinado entre el centro residencial, la familia y la comunidad. Por otra parte, el proceso de desinternación debe comenzar cuando el menor ingresa al centro, a fin de implementar intervenciones que promuevan su salida (Unicef 2002).

La experiencia de la Región de Valparaíso es citada como un caso exitoso de desinternación, porque en doce años han sido capaces de aumentar el porcentaje de niños en familias de acogida de 7 a 22 por ciento, aumentando el porcentaje de familias externas a 48 por ciento (Relaf et al. 2013). Pero no existe información respecto de la calidad de la atención que reciben.

Aparte de estas iniciativas específicas, en años recientes el Sename ha ido instando a los centros residenciales a elaborar planes de egreso y trabajar con las familias en pos de su reunificación. Para los niños más pequeños, las estadías prolongadas ya no son la norma. Para los mayores es más difícil generar soluciones alternativas y tienen más probabilidades de permanecer internados hasta cumplir la edad de egreso (18 años).

\section{Desinternación: el marco erróneo para la reforma}

El objetivo del sistema debiera ser ayudar a esos niños a recuperarse de su trauma y maltrato, proveer de un entorno saludable, seguro y estimulante, en un contexto familiar, en lo posible, con sus familias de origen. 
Como se señaló en la sección anterior, la desinternación no es una política nueva. Ahora, los niños no son internados de manera indefinida y todos los actores declaran que el objetivo es la reunificación de la familia. Pero algo está fallando.

La investigación y las entrevistas realizadas indican que una de las falencias consiste en no tener una mejor y más profunda comprensión del problema para generar soluciones efectivas: no existen alternativas válidas a la internación para soluciones temporales y no se están realizando muchas acciones concretas para posibilitar una reunificación familiar.

El objetivo de política debiera ser encontrar el mejor lugar temporal para el menor con los servicios requeridos para su recuperación mientras se busca un destino permanente. Si se plantea como objetivo la desinternación se corre el riesgo de sacar a los niños de las instituciones sin disponer de un lugar permanente para ellos. Asimismo, puesto que la desinternación no es la solución universal, la política debería considerar la opción de mejorar la atención en centros residenciales, ya que para algunos menores ésa es su mejor ubicación.

Antes de proceder a una desinternación es preciso que sucedan al menos tres cosas:

Primero, el Sename debe contar con un buen diagnóstico de quiénes son los niños en el sistema, cuáles son sus problemas y los de sus familias. Los perfiles de los menores han cambiado con el tiempo y ahora son más complejos. Están relacionados con el alcohol y el consumo de drogas durante el embarazo y problemas psiquiátricos o psicológicos que requieren soluciones especializadas. Esta mejor comprensión del problema debiera permitir al Sename segmentar la población y diferenciar los servicios según las necesidades de cada niño.

Segundo, el Sename debiera implementar modelos de atención alternativos y evaluar cuál representa una mejor solución para los diferentes tipos de casos. Por ende, más que un programa, lo que se requiere es una gama de soluciones para enfrentar diferentes problemas.

Tercero, si el objetivo último es la reunificación familiar, es preciso proveer intervenciones y servicios variados para ayudar a las familias. En la actualidad, el menor es separado temporalmente de su familia a la espera de que ésta adquiera las competencias para recibirlo de vuelta, pero no siempre existen recursos o intervenciones para ayudar a la familia en ese proceso. 
Estos tres aspectos nos llevan a las recomendaciones de política expuestas en este artículo y que son abordadas en la siguiente sección.

\section{RECOMENDACIONES DE POLÍTICA: ENCONTRAR Y ADAPTAR LA MEJOR SOLUCIÓN PARA EL CONTEXTO CHILENO}

\section{Mejor uso de la información}

\subsection{Comprender a los niños y sus problemas}

Puesto que la desinternación no es una directriz nueva y los Tribunales de Familia han calificado la internación como la última opción, es importante analizar los perfiles de los menores que están bajo tutela estatal. En la actualidad, sólo los casos más complejos terminan en centros residenciales, ${ }^{28}$ a veces porque esfuerzos previos han fracasado. Por ello, en lugar de implementar una estrategia única, es importante que el Consejo Nacional de la Infancia comprenda quiénes son los niños que viven en las instituciones y cuáles son los problemas que los aquejan.

¿Qué información se encuentra disponible? Hasta ahora, el Sename se ha basado en sus propios datos. Pero, como ya se señaló en la sección III, esta información no es suficiente: no explica por qué los niños están ahí, cuál es su situación familiar ni los problemas subyacentes que los aquejan.

¿Qué información se requiere? El Consejo Nacional de la Infancia necesita información relativa al niño o la niña, a las características de su familia y a la calidad de los centros residenciales y programas de acogimiento.

Con respecto a los menores, no es necesario recabar nueva información; se puede lograr un gran cambio con sólo unir las bases de datos de otros ministerios y de los Tribunales de Familia. ${ }^{29}$ Las fuentes más relevantes serían:

28 Según la información obtenida en las entrevistas realizadas a académicos expertos en esa área.

${ }^{29}$ Cada individuo residente en Chile tiene un número de identidad y toda la información que le concierne es registrada en los diferentes ministerios bajo el mismo número. La excepción es el Ministerio de Salud, cuyos registros de prestación de servicio no son identificables por individuo. 
- Registro Civil: Dispone de información sobre todos los familiares y sus respectivos domicilios. Un acuerdo de cooperación entre el Sename y el Registro Civil, ambas entidades dependientes del Ministerio de Justicia, permitiría que el Sename tenga un acceso expedito a los registros de la familia del menor. En la actualidad, para cada caso se debe solicitar acceso; asimismo, obtener información sobre los parientes, a fin de rastrear a un familiar que pueda hacerse cargo, toma una cantidad de tiempo considerable que podría reducirse, acelerándose así el proceso de hallar un lugar de destino estable.

- Tribunales de Familia: Cuentan con registros electrónicos completos para dar seguimiento a cada menor. Existen conversaciones iniciales para conectar este sistema con Senainfo y tener un solo sistema de seguimiento con información más detallada. Ésta es una iniciativa que el Consejo Nacional de la Infancia debiera promover.

- Ministerio de Educación: Cuenta con datos sobre cada estudiante, tales como características personales, asistencia, desempeño escolar y resultados en las pruebas. Esta información podría utilizarse como proxy, o aproximación, de resultados del menor y comparar los resultados de diferentes lugares de destino.

- Ministerio de Desarrollo Social: El Registro de Información Social (RIS) contiene todos los beneficios sociales que recibe una persona de diferentes ministerios. Adicionalmente, cuenta con registros individuales con todas las características utilizadas para focalizar programas sociales.

Consolidar esta información permitiría obtener una caracterización precisa de la familia y de los servicios que está recibiendo. En lo que respecta a los centros residenciales, la información observada por los supervisores del Sename en sus visitas mensuales debe ser sistematizada y analizada.

Como ya se mencionó, no todos los centros residenciales son deficientes y algunos podrían brindar atención de alta calidad. Por ello, la información relativa a las características del centro residencial (número de cuidadores, hogares familiares versus hogares masivos, tasas de rotación de personal, servicios brindados, etcétera) debe ser considerada antes de decidir cuáles serán clausurados. 


\subsection{Establecer un sistema de monitoreo}

A pesar de que el Sename realiza supervisiones periódicas, la información no es digitalizada y no está disponible para un posterior análisis. Las autoridades del Sename mencionaron en las entrevistas que estaban trabajando en la elaboración de un sistema de información en línea. Este último podría utilizarse para establecer un sistema de monitoreo con indicadores financieros, de desempeño y de resultados; con mecanismos de alertas e informes, y usar esta información para una mejor toma de decisiones. Esto podría servir para comprender mejor las características de esta población y contribuir a tomar decisiones oportunas, evitándose así institucionalizaciones prolongadas.

Implementar esta recomendación es simple, pero se requieren cambios en la política y capacidad organizacional. Esto será discutido al momento de abordar la factibilidad de la reforma.

\section{Crear modelos de atención alternativos para evitar la internación}

\subsection{Intervenciones especializadas adaptadas a las necesidades de cada niño}

Como ya se ha señalado en secciones anteriores, es necesario tener una comprensión acabada de los problemas de estos niños antes de diseñar la solución. Una vez que la información antes descrita ha sido analizada, el Consejo Nacional de la Infancia, en conjunto con el Sename, debería proponer una gama de soluciones. Ésta no debiera plantearse como una disyuntiva entre familias de acogida y centros residenciales, sino como un continuo con diferentes grados de institucionalización para responder a las necesidades de cada niño.

Contar con información fidedigna sobre la situación del menor junto con información sobre los resultados de casos similares anteriores y una gama de soluciones posibles debiera permitir que el juez encuentre el mejor lugar de destino para cada niño. El juez necesitará contestar preguntas tales como: “¿Es beneficioso que el niño o la niña permanezca con sus padres?", y luego, a partir de la respuesta, se abren diferentes opciones de programas. El diagrama 2 ilustra el proceso de decisiones, simplificado, que debe atravesar un juez. 
Diagrama 2. PROCESO DE DECISIÓN DE UN JUEZ DE FAMILIA

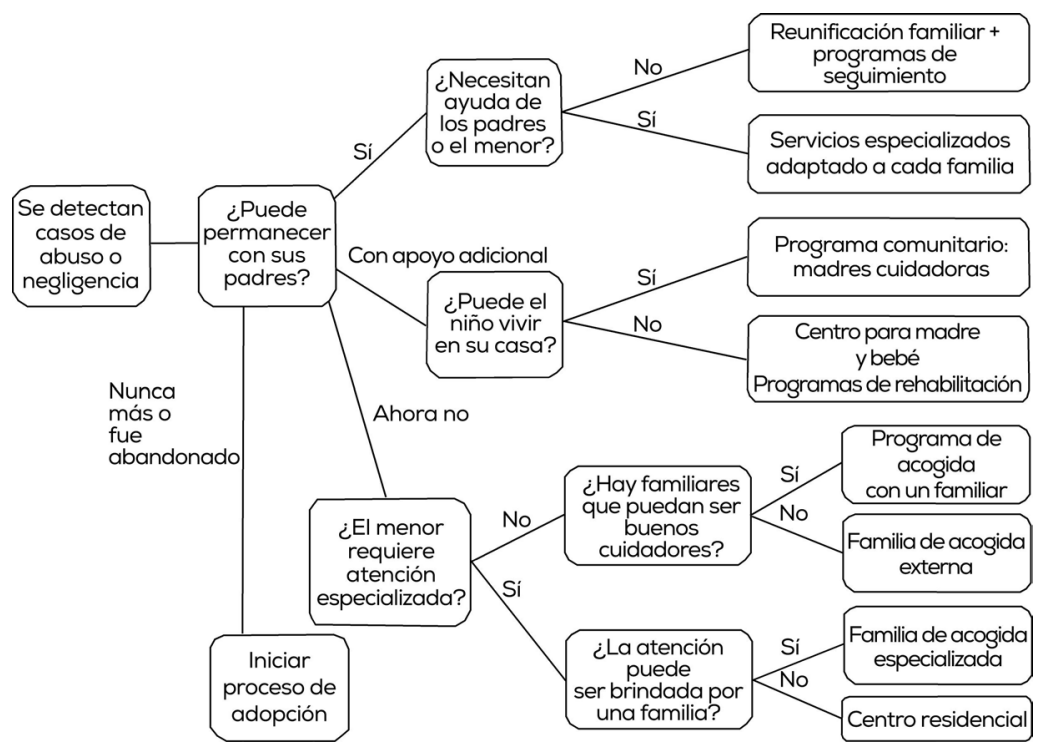

La gama de opciones debiera abarcar desde la adopción, cuando los padres no están dispuestos o no tienen la capacidad de asegurar la custodia del menor, hasta la permanencia del menor con la familia, recibiendo servicios especializados según las necesidades de la familia.

Algunas de estas alternativas ya existen, pero la propuesta consiste en organizarlas como un continuo de soluciones y fortalecer esos programas como alternativas legítimas a la internación. El rediseño y la creación de nuevos programas deberían basarse en evidencia de lo que ha demostrado ser efectivo y en datos relacionados con estos problemas, dónde están localizados estos niños y qué servicios están recibiendo.

Por ejemplo, de las entrevistas realizadas para este trabajo surgió la necesidad de un nuevo programa, debido a que existían numerosos casos de recién nacidos que ingresaban al sistema y que provenían de madres consumidoras alcohol o drogas durante el embarazo. En el esquema vigente, el bebé es enviado a un centro residencial y la madre es derivada a un servicio de rehabilitación. En más de un caso reciben a más de un bebé de la misma madre. Esto levantó la propuesta de que sería mejor trabajar con la madre en su rehabilitación. Actualmente no 
se ofrece esta solución, porque el subsidio del Sename es por niño y no cubre los costos de la rehabilitación de la madre. La solución debe combinar los servicios brindados por los diversos ministerios. La evidencia internacional debería colaborar también en su diseño.

Esta recomendación requerirá la creación de más capacidades en el Sename, así como el incremento de recursos para la gestión y la prestación de servicios. En el diagrama 3 se resume una posible escala de opciones.

Diagrama 3. RESUMEN DE SOLUCIONES ALTERNATIVAS

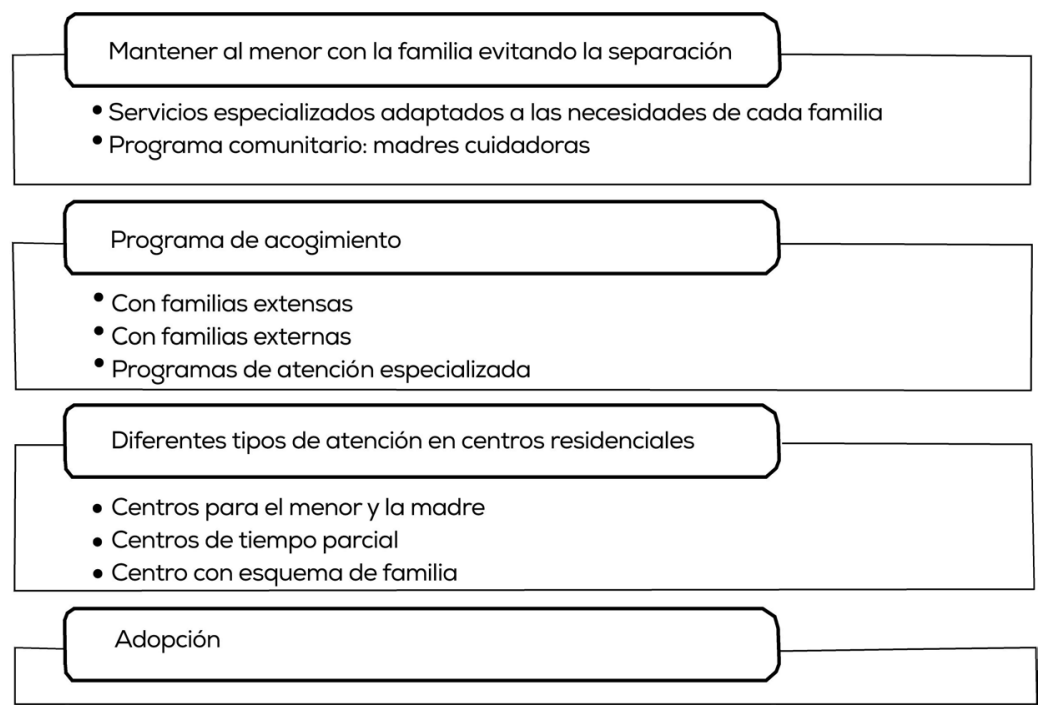

El sistema vigente no ha logrado alinear soluciones efectivas en función de necesidades específicas. Prueba de ello son las altas tasas de reingreso y que la mayor cantidad de solicitudes de internación provenga, justamente, del resto de programas del Sename.

Antes de diseñar cada intervención, el Consejo Nacional de la Infancia debe analizar la información expuesta en la primera recomendación. Luego, debe valerse de la evidencia de lo que funciona y enfocarse en la elaboración de políticas basadas en evidencia, proceso en el cual la información es utilizada para diseñar, implementar, poner a prueba y rediseñar. Este artículo sólo se explayará en la presentación de 
una propuesta para la atención en programas de acogimiento, dejando las restantes soluciones como un área a explorar una vez que se cuente con un mejor diagnóstico.

\subsection{Programas de familias de acogida}

El propósito de esta sección es abordar el problema de la internación, proponiendo una intervención integral que brinde una respuesta efectiva para los menores de ocho años.

La teoría de cambio subyacente dice que contar con padres más preparados en familias de acogida, junto con un sistema de apoyo e intervenciones para ayudar a los menores a recuperarse del daño que han sufrido, favorecerá su reinserción en la vida social y permitirá que se desarrollen como adultos íntegros.

Como ya se dijo, no se trata de trasladar a los niños a familias cuidadoras. Los niños necesitan cuidados nutritivos para desarrollar un apego organizado hacia sus cuidadores, así como cuidadores estables, que se puedan comprometer con ellos, que los ayuden a crear un sentido de identidad y a regular su comportamiento (Dozier et al. 2013). Los programas de acogimiento debieran ser complementados por intervenciones que fortalezcan el bienestar de los cuidadores y de los menores (Casanueva 2013).

Asimismo, para que las familias de acogida sean una solución temporal, deben ser complementadas con políticas y servicios que posibiliten la reunificación familiar, punto abordado en la tercera propuesta.

\section{i. ¿Por qué las familias de acogida no han funcionado en Chile?}

El estudio realizado por Relaf et al. (2013) indica algunas posibles causas por las que las familias de acogida no han funcionado en Chile, causas que también fueron señaladas en las entrevistas realizadas para este trabajo:

-Escasa visibilidad de este programa y baja disponibilidad de familias de acogida.

-Creencia en que los niños están mejor protegidos en centros residenciales.

-Control y supervisión limitados de los hogares de familias de acogida. 
- Los programas de acogimiento son percibidos como un atajo para la adopción por parte de familias que no cumplen con los requisitos para adoptar.

-Falta de conocimiento sobre el daño que puede producir la internación.

-El sistema actual no cuenta con los recursos para trabajar con familias de acogida o de origen.

En las entrevistas los comentarios fueron que no hay familias externas dispuestas a asumir los cuidados de los niños, las familias actuales no tienen la capacidad de cuidar a esos niños y no hay recursos para ayudarlos o para monitorear a los menores para asegurarse de que estén en buenas condiciones.

ii. ¿Por qué han fracasado los intentos anteriores de fortalecer este programa?

La pregunta respecto a los fracasos anteriores de este programa es clave y debe ser contestada antes de diseñar un nuevo programa. Desde la perspectiva de las ONG, el fracaso se debe a que el Gobierno no ha sido capaz de crear conciencia en la población acerca de este programa o de contribuir a reclutar familias de acogida. Además, el financiamiento ha sido insuficiente. Sin embargo, puede que existan otras razones que no han sido exploradas.

\section{iii. Diseño de un programa efectivo de familias de acogida}

Como ya se señaló, el programa debe contar con ciertas características para lograr su propósito de recuperar a los menores. Algunos elementos claves de este nuevo programa son:

- Fortalecer la atención con familias externas: generar conciencia social y una cultura de cambio. El programa actual se basa en las familias extensas. Evaluaciones del programa actual concluyeron que no ha habido un esfuerzo coordinado para llegar a familias de acogida externas (Martínez 2011). Si el programa quiere dar respuesta a más niños, no puede depender exclusivamente de las familias extensas. El primer paso es reclutar nuevas familias. Los obstáculos para hacerlo son los siguientes: 
-Falta de conocimiento acerca de este programa.

-Recursos insuficientes para reclutar.

-Reducir el estigma asociado a los niños que provienen del Sename. ${ }^{30}$

-Promover una cultura de familias de acogida a través de modelos de roles que hayan brindado con éxito este servicio a la comunidad.

-Trabajar con iglesias y organizaciones que tengan un mayor sentido de comunidad donde pueda darse inicio a un modelo colaborativo de acogida.

- Preselección más rigurosa. Esto es clave para asegurar una atención segura y de calidad. Si se realiza un mejor proceso de reclutamiento se podría contar con una cantidad de padres suficientes para seleccionar a los más idóneos. La selección debiera basarse en criterios tales como sostenibilidad económica, estabilidad familiar, ausencia de antecedentes de violencia y otras características relacionadas con la paternidad. El proceso de selección también debiera aplicarse a la atención con familias extensas, aunque podría justificarse que se usaran otros estándares.

- Facilitar el trabajo: diseñar un esquema de apoyo. Ser un padre de acogida es una ardua tarea. La paternidad es compleja, pero en este caso es aún más desafiante, puesto que es probable que el niño tenga secuelas de maltrato o abandono.

Un apoyo permanente a las familias puede ayudar a generar mayor sentimiento de eficacia entre los padres de acogida y disminuir el estrés parental. Esto, a su vez, acrecienta la motivación y la capacidad de brindar un cuidado más sensible, lo que se relaciona con la seguridad en el apego, ya que puede conducir al desarrollo de un apego seguro con el padre de acogida (Shonkoff 2000). Este esquema de apoyo puede traducirse en visitas al hogar, redes de apoyo con otros padres de acogida y acceso preferencial a los servicios de salud y otros programas de protección social. Un tema recurrente que surgió en las entrevistas es que el programa de familias de acogida tenía que poder satisfacer, con sus escasos recursos, las necesidades socioeconómicas de la familia. Esto podría solucionarse conectando a las familias con los programas sociales existentes.

${ }^{30}$ En la actualidad, como el Sename dirige a la vez los programas para niños y jóvenes infractores y programas para niños y jóvenes vulnerados en sus derechos, la reputación de los primeros ha afectado a los demás, pero esto debiera cambiar si el servicio se divide. 
- Incentivos económicos: aumentar el pago a los padres de acogida. El monto que debiera recibir una familia de acogida es un tema controversial. Por una parte, debiera cubrir las necesidades del menor, pero algunos argumentan que no debiera ser muy elevado para que la gente no acoja menores por razones erróneas. Como se señala en la sección II, 2.2, el pago actual es inferior a lo que sugiere la evidencia internacional. El monto exacto debiera ser estudiado en detalle, pero está claro que debiera ser mayor y un buen proceso de preselección debiera descartar a los padres con motivaciones erróneas. Mayores aportes de dinero podrían incentivar a las familias con costos alternativos más elevados a ser familia de acogida. Asimismo, el monto debiera variar según el grado de especialización de las familias, ya que los menores que requieren una dedicación exclusiva debieran estar asociados a una mayor compensación económica.

- Cambios en el sistema regulatorio: prioridad para la adopción. La atención en familias de acogida es una solución temporal y no debiera concebirse como un atajo para adopción en familias que no cumplen con los requisitos para ser padres adoptivos. Pero si el niño termina siendo dado en adopción, los padres de acogida, si están dispuestos a ello, debieran tener prioridad. Actualmente, no pueden hacerlo y esto requiere una modificación a la Ley de Adopción. De todas formas, la posibilidad para los padres de acogida de adoptar no debe interferir en la reunificación del niño con su familia de origen.

\section{iv. Desarrollar diferentes tipos de familias de acogida}

El programa actual se encuentra dividido en dos: el Programa de Familias de Acogidas Simples (FAS) y el Programa de Familias de Acogidas Especializadas (FAE), pero en la práctica son iguales y reciben el mismo tipo de apoyo. Para lograr mejorar estos programas, el Sename debiera dividir la atención de acogida en familias extensas, atención de acogida en familias externas, atención de acogida especializada y atención de acogida de preadopción. Se debiera buscar familias con diferentes perfiles y grados de especialización y ofrecerles diferentes montos de dinero y tipo de apoyo. 


\subsection{Atención en centros residenciales}

El programa actual de familias de acogida debe atravesar muchos cambios para brindar servicios a más menores y con mejores familias, pero, tal como se ha señalado, esto no funcionará para todos los casos. Por ello, mientras se realizan los cambios en los programas de familias de acogida y estos demuestran ser efectivos, la atención en centros residenciales seguirá siendo la principal alternativa.

Los implementadores entrevistados se quejaron de que la reforma propone atención en centros residenciales únicamente en casos excepcionales y el Consejo Nacional de la Infancia olvida que, como sólo se reciben casos complejos, los casos de excepción podrían ser la regla. La internación seguirá siendo la principal respuesta hasta que se desarrolle un buen programa con familias de acogida externas y especializadas.

Las directrices para los centros residenciales debieran seguir insistiendo en la atención personalizada, planes de egreso para cada menor, reducción de la proporción de niños por cuidador y organización de centros residenciales en casas pequeñas. Del mismo modo, se deben invertir más recursos para que los centros residenciales puedan contratar a mejores profesionales, reducir la rotación e invertir en trabajo con las familias de origen.

\section{Coordinar la prestación de servicios para promover la reunificación familiar}

Todas las soluciones presentadas más arriba están concebidas como temporales mientras se espera un lugar de destino permanente con la familia de origen o adoptiva. Pero los niños permanecen más tiempo de lo supuesto en estos lugares provisorios.

El sistema actual está fallando en su trabajo con las familias de origen y la prestación de servicios no está solucionando sus problemas. La mayoría de las intervenciones consiste en talleres para desarrollar habilidades parentales, pero no hay conexión formal con otras redes de servicios para resolver los problemas subyacentes que afectan a esas familias. Como se señaló en la caracterización de los menores, la problemática familiar suele estar relacionada con el consumo problemático de alcohol y el abuso de drogas. En la mayoría de los casos, la reunificación familiar no va a ser exitosa si no se resuelven esos problemas. 
El Sename tiene la responsabilidad de restituir los derechos que han sido vulnerados y de reinsertar estos niños en la vida social. Sin embargo, existe una multiplicidad de derechos y en su mayoría caen bajo la responsabilidad de otros ministerios. Por ejemplo, el derecho a la educación y a no ser obligado a realizar trabajo infantil dependen de otros ministerios, en este caso de Educación y del Trabajo. Lo mismo ocurre con el derecho a recibir atención de salud y a vivir en familia. Para estos temas transversales la solución debe enfocarse en el menor y requiere una coordinación interinstitucional (Focus 2013).

\subsection{Red de atención de salud}

Los entrevistados revelaron que el problema más común que afecta a las familias es el consumo de drogas. Sin contar con datos y hablando a partir de su experiencia, señalaron que aproximadamente el 90 por ciento de los padres consumían drogas. Se requiere un diagnóstico preciso de esta situación para diseñar un programa acorde.

Lo que sucede en casos de problemas mentales o de consumo de drogas es que los padres son enviados a servicios públicos de salud (Centros Comunitarios de Salud Mental, Cosam), pero estos no están disponibles en todo el país o no hay suficientes vacantes. Como los sistemas de información no están conectados entre sí, el Sename no sabe si están recibiendo el programa.

Para solucionar este problema, el Sename debe establecer un acuerdo de cooperación con el Ministerio de Salud y el Servicio Nacional para la Prevención y Rehabilitación del Consumo de Drogas y Alcohol (Senda), dependiente del Ministerio del Interior.

El Ministerio de Salud y el Senda debieran implementar una red especial de servicios para ayudar a las familias en situación de riesgo de que su hijo sea internado. El Sename por sí solo no tiene las competencias para resolver los problemas que arrastran estas familias. El Consejo Nacional de la Infancia, como entidad a cargo de diseñar las políticas, debe asegurar que se realicen y sean implementados estos acuerdos. Como el Ministerio de Salud es parte del Consejo Nacional de la Infancia, la coordinación debiera ser más fácil de lo que lo fue en el pasado para el Sename. 


\subsection{Red de protección social}

Chile cuenta con una red de programas de protección social (Ley n. $\left.{ }^{\circ} 20.379\right)^{31}$ que tiene diferentes criterios de elegibilidad, donde las familias que cumplen con ciertos criterios de vulnerabilidad tienen acceso prioritario a los servicios del Estado. Las familias cuyos hijos han sido internados debieran tener acceso prioritario, de manera que el Sename se centre en la intervención hacia el menor y deje las necesidades socioeconómicas de la familia en manos de los servicios dedicados a esa materia. La reunificación familiar sólo será posible mediante un esfuerzo conjunto entre las entidades públicas.

Hasta el momento, la cooperación entre entidades públicas ha sido escasa y el Sename no tiene potestad para exigirles a los otros ministerios que provean los servicios requeridos. En cambio, en virtud de la Ley de los Tribunales de Familia, el Sename tiene la obligación de brindar los servicios que dicten los Tribunales, pero no puede forzar a otras entidades a cooperar. La coordinación y el apoyo de otros ministerios, especialmente los de Salud, Desarrollo Social, Educación, así como los servicios de Senda, son cruciales. La diferencia respecto de iniciativas anteriores es que ahora el Consejo Nacional de la Infancia, entidad a cargo de la reforma, tiene autoridad para asegurar la cooperación entre los diferentes organismos gubernamentales. ${ }^{32}$

\section{FACTIBILIDAD DE LA REFORMA}

\section{Idoneidad técnica}

Para la primera y tercera propuestas —el mejor uso de la información y la coordinación de servicios en aras de la reunificación familiar- la idoneidad técnica no es el desafío. Las dificultades residen en la política organizacional, las capacidades y la coordinación con otros ministerios.

${ }^{31}$ Se puede encontrar una breve descripción de los programas existentes en "Red de programas y beneficios del Ministerio de Desarrollo Social y sus servicios relacionados", en www.ministeriodesarrollosocial.gob.cl/centro-informacion/proteccion-social-todos-todas. Fecha de consulta: 27 de enero de 2015.

${ }^{32}$ Como Chile tiene un gobierno centralizado, todos sus acuerdos de cooperación tienen que ser suscritos a nivel central y luego hay que asegurarse de que sean ejecutados a nivel local. 
Para la segunda propuesta, una solución técnicamente idónea debiera sustentarse en evidencia válida para el contexto específico. En este caso, no existe suficiente evidencia respecto de lo que funciona para el contexto chileno como para poder confiar que el programa es técnicamente idóneo en su diseño. Implementar un sistema de atención en familias de acogida basado en un modelo de mejores prácticas de otro país probablemente no funcione en Chile, ya que la política tiene que adaptarse a las normas y los mecanismos culturales que caracterizan la situación actual.

La solución técnicamente correcta propuesta para el Consejo Nacional de la Infancia es iniciar con el Sename un proceso de encontrar y adoptar una solución que responda al contexto chileno. Como el tamaño de la muestra es pequeño y las intervenciones no son estandarizadas, es probable que desarrollar una evaluación de impacto experimental no sea la forma de descubrir lo que funciona.

Por ello, la estrategia propuesta consiste en realizar un proceso de aprendizaje basado en la experiencia (Pritchett et al. 2013) y, en lugar de comenzar con un diseño único, hacerlo con varios diseños pilotos simultáneamente, para ver cuál es la mejor forma de abordar un problema particular en un contexto específico. Esto permite probar diferentes alternativas y buscar el diseño más adecuado.

Para cada elemento clave del programa de familias de acogida el proceso de diseño debiera comenzar por buscar una "desviación positiva" (Marsh et al. 2004). Esto significa buscar una ONG que esté realizando una buena labor en ese aspecto. Por ejemplo, comenzar por responder si existen ONG que estén realizando una buena labor en materia de reclutamiento de familias externas. Si se encuentra un buen ejemplo, el paso siguiente es comprender cómo funciona y si es replicable.

Sin embargo, según la información obtenida en las entrevistas, es probable que no exista una ONG que esté realizando una labor destacada en estos aspectos. En ese caso, la recomendación es investigar sobre mejores prácticas a nivel internacional y analizar cómo adaptarlas al contexto nacional.

Este proceso de aprendizaje requiere un sistema de monitoreo con mecanismos de retroalimentación adecuados. Implica definir indicadores, establecer mecanismos de medición, registrar la información, analizarla y extraer lecciones. Esta información debiera ser compartida con 
todos los actores involucrados e incorporada en el rediseño de las intervenciones. El Sename debiera implementar este proceso para todos los modelos de atención alternativos discutidos en la segunda propuesta.

\section{Factibilidad administrativa}

Las tres propuestas presentan varios desafíos en cuanto a su implementación en la medida en que requieren un cambio en la cultura organizacional y en las capacidades del Sename. El desafío se refiere, en primer lugar, a comenzar a utilizar la información disponible y elaborar políticas basadas en evidencia; segundo, crear capacidades y generar recursos para monitorear de manera efectiva, medir resultados y transformarse en una organización de aprendizajes; y tercero, coordinar con otras entidades públicas para el uso de información y para crear redes de apoyo para las familias. El Sename se beneficiará de promover una cultura orientada a los resultados, pero es esperable que haya resistencia al cambio.

Para implementar esta reforma, el Sename requiere más recursos y necesita construir capacidades dentro de la organización y en los OCA. Una de las razones que explica el fracaso de las reformas anteriores es el hecho de que no disponían de los recursos necesarios ni de profesionales capacitados.

Un factor clave para implementar un servicio de acogida de calidad es contar con un número adecuado de profesionales calificados. Los desafíos relacionados con reclutar, seleccionar y retener a un personal calificado en materia de protección de menores son enormes, pero deben ser enfrentados, ya que los servicios de protección de menores efectivos requieren de un personal capaz de brindar intervenciones especializadas. Más aún, es de suma importancia incrementar la satisfacción laboral para minimizar la rotación de personal (Pecora et al. 2009).

Con el fin de que la implementación sea exitosa, el Sename debe diseñar contratos rigurosos y establecer procesos claros de monitoreo, supervisión y medición. Los contratos deben ser definidos en dos niveles: primero, entre el Sename y los OCA; y luego, entre los OCA y las familias de acogida.

Para el primer nivel, tal como se analizó en la sección III, 2.1, el mercado de los OCA está muy concentrado: pocas organizaciones par- 
ticipan en los procesos de licitación y los subsidios no logran cubrir los costos. Es preciso entregar más recursos, para hacer atractivo el ingreso a nuevos proveedores y elevar los estándares de estas organizaciones. Si los nuevos requerimientos no van acompañados de recursos adicionales es imposible que las ONG puedan cumplir. Lo que ha sucedido en el pasado es que las ONG prefieren trabajar de manera independiente, consiguiendo aportes de privados y sin la supervisión del Sename. En este escenario, sólo los proveedores de baja calidad, que no logran acceder a subvenciones del sector privado, estarán dispuestos a trabajar con el Sename.

El Sename puede optar por seguir brindando servicios de baja calidad a un bajo costo o probar otras opciones. Una vía posible sería comprometerse con una solución particular, por ejemplo, preservar las familias. Dada la heterogeneidad de los problemas existentes, esta alternativa no permitirá lograr resultados satisfactorios. Otra posibilidad es adoptar un enfoque más pragmático valiéndose de los datos existentes y creando una cultura basada en la evidencia, con más recursos, sueldos más elevados para los asistentes sociales y mayores aportes económicos para las familias.

Una vez que los OCA son seleccionados a través del proceso de licitación, si no tienen una motivación intrínseca para brindar una atención de calidad, no tendrán los incentivos para hacerlo. Para evitar esta situación, el Sename debería establecer un pago fijo y un bono para incentivar el buen desempeño en base a factores medibles y relevantes para la atención prestada.

En sus contratos con las familias de acogida, los OCA deben establecer incentivos para los padres de acogida, considerando su motivación intrínseca y los recursos necesarios para respaldar su comportamiento.

\section{Apoyo político}

Para las propuestas presentadas, el Sename necesita más recursos y comprometer a otros ministerios para que compartan sus datos y colaboren en la prestación de servicios para la tercera propuesta. Esto requerirá apoyo político dentro del Gobierno y del Congreso. 


\subsection{Análisis de los grupos de interés}

Un primer paso para analizar el grado de apoyo que tendrá esta reforma es observar quién liderará el cambio y quién lo apoyará o resistirá. Como lo estableció la Presidenta Bachelet, el Consejo Nacional de la Infancia liderará el cambio. Esta organización está empoderada para realizarlo, sin embargo, no es el organismo que lo implementará. Esto tiene ventajas, pero requiere que se construya legitimidad para el Consejo Nacional de Infancia en su rol como el líder del cambio, al tiempo que se debe involucrar al Sename en la implementación de la reforma.

El Sename, como ejecutador del programa, debe estar comprometido con la reforma, pero tiene capacidades limitadas para liderar el cambio. Este organismo se encuentra en un escenario complejo, en el que su desempeño y legitimidad han sido cuestionados. Se ha visto implicado en varios escándalos de abuso a menores y ha sido acusado por la prensa, el Congreso y el sistema judicial de no ser capaz de velar por los derechos de los niños (Guzmán 2013; Cámara de Diputados 2014; Corporación Administrativa del Poder Judicial 2013).

Como se señaló en la introducción de este estudio, invertir en estos niños tiene el potencial de producir grandes ahorros para el país en las siguientes décadas. Si se implementa bien, este proceso se puede traducir en una baja potencial de las tasas de reclusión, delincuencia y problemas conductuales, con sus costos asociados. A la vez, puede incrementar las ganancias que producirán estos menores cuando se transformen en adultos funcionales. Sin embargo, para ello se requiere de actores políticos con una visión de largo plazo, ya que tendrán que incurrir en costos sin ver los retornos durante su período activo.

Algunos centros residenciales se oponen a la desinternación, no sólo porque "pierden su trabajo", sino también porque creen en su propio modelo. Observando cómo funcionan los programas de acogimiento no creen que éstos sean una mejor respuesta. Más aún, para cumplir con la regulación internacional y los nuevos estándares, los centros han ido cambiando progresivamente su modelo hacia grupos más pequeños, con una proporción más baja de niños por cuidador y entregando atención personalizada. Con estos cambios piensan que están brindando el tipo de atención que requieren los niños.

Las organizaciones que trabajan con familias de acogida deberían estar entusiasmadas con la reforma, pero, de acuerdo con las entrevis- 
tas realizadas, estas organizaciones son críticas respecto de la labor del Sename y discrepan de que la desinternación masiva sea la política adecuada.

\subsection{Concitar apoyos}

Los cambios propuestos requieren mayores recursos, que deben ser aprobados por el Ministerio de Hacienda y luego por el Congreso. La baja legitimidad del Sename como instancia de protección de los menores puede jugar a favor (consenso de que necesitan más financiamiento) o en contra (no son capaces de implementar una reforma).

Sin embargo, la desaceleración de la economía y las múltiples reformas que el Gobierno está llevando a cabo generan un escenario complejo para un aumento significativo del financiamiento. Por ello, comenzar con planes piloto y mostrar resultados podría servir para ganar legitimidad y concitar apoyos.

A pesar de que los centros residenciales que trabajan en pos de la protección de los menores no son organizaciones poderosas, su apoyo es esencial para la implementación de la reforma, para mejorar la calidad de su atención y, en algunos casos, para comenzar a ejecutar los nuevos programas de familias de acogida.

\subsection{Desafios para promover cambios que beneficien a una población sin voz propia}

La desinternación per se tiene pocas probabilidades de lograr éxito, pero estas tres propuestas de política son técnicamente correctas e implican crear capacidades que debieran concitar un mayor apoyo.

Esta reforma beneficiará a una población vulnerable y sin voz propia. Para seguir adelante, es preciso involucrar a los diversos actores. El Consejo Nacional de la Infancia debe formar una coalición en la que el Sename cumpla un rol determinante y en la que se incluyan a los OCA encargados de implementar los cambios. Ellos dispondrán de una información de primera fuente sobre la población destinataria y una comprensión de qué factores podrían hacer fracasar un programa de familias de acogida. 
La reforma debiera comenzar por generar conciencia de que los niños que han padecido abuso y negligencia están en peligro de transformarse en adultos disfuncionales si no se realizan las intervenciones necesarias. El Consejo Nacional de la Infancia y el Sename deben legitimar los modelos alternativos de atención a menores y mostrar que pueden tener un impacto positivo en la recuperación de los niños y en su reintegración a la vida familiar.

\section{REFERENCIAS CITADAS}

Aldeas Infantiles SOS Internacional \& Relaf. 2010. Informe Latinoamericano. Situación de la niñez sin cuidado parental o en riesgo de perderlo en América Latina. Contextos causas y respuestas. Buenos Aires, Argentina. http://www. relaf.org/ Informe\%20Latinoamericano.pdf.

Álvarez, Jorge. 2013. "Historia de adolescentes egresados de la red de protección del Sename y factores de riesgo de ingresar a la justicia juvenil". Señales 9. Sename. Ministerio de Justicia.

Baglivio, Michael, Nathan Epps, Kimberly Swartz, Mona Sayedul Huq, Amy Sheer \& Nancy Hardt. 2014. "The Prevalence of Adverse Childhood Experiences (ACE) in the Lives of Juvenile Offenders". Journal of Juvenile Justice 3 (2).

Barbell, Kathy \& Madelyn Freundlich. 2001. Foster care today. Washington, DC: Casey Family Programs. www.hunter.cuny.edu/socwork/nrcfcpp/downloads/ policy-issues/foster_care_today.pdf.

Bernard, Kristin, Mary Dozier, Johanna Bick, Erin Lewis-Morrarty, Oliver Lindhiem \& Elizabeth Carlson. 2012. "Enhancing Attachment Organization Among Maltreated Children: Results of a Randomized Clinical Trial". Child Development 83 (2): 623-636. doi: 10.1111/j.1467-8624.2011.01712.x.

Berrick, Jill Duerr \& Aron Shlonsky. 2001. "Assessing and Promoting Quality in Kin and Nonkin Foster Care". Social Service Review 75 (1): 60-83. doi: $10.1086 / 591882$.

Browne, Kevin. 2009. The Risk of Harm to Young Children in Institutional Care. www.savethechildren.org.uk/sites/default/files/docs/The_Risk_of_Harm_1. pdf.

Cámara de Diputados. 2014. "Informe de la comisión especial investigadora del funcionamiento del Servicio Nacional de Menores (Sename)". Cámara de Diputados de Chile. 4 de marzo. www.camara.cl/pdf.aspx?prmID=10892\&pr mTIPO=INFORMECOMISION.

Casanueva, Cecilia. 2013. "Developing Family Foster Care in Chile: The Nest Family Project”. RTI International. Inédito, se puede solicitar a la autora.

Chía, Enrique, Candice Fischer \& Carolina Muñoz. 2014. "Lineamientos estratégicos para modelos de cuidado alternativo dirigidos a niños/as 
menores de seis años bajo protección estatal". En Concurso de Políticas Públicas / 2013. Propuestas para Chile, editado por Ignacio Irarrázaval, María de los Ángeles Morandé y Magdalena Letelier. Santiago: Centro de Políticas Públicas UC. http://www.academia.edu/5747658/Lineamientos_ estrat\%C3\%A9gicos_para_modelos_de_cuidado_alternativo_dirigidos_a_ ni\%C3\%B1os_as_menores_de_seis_a\% $3 \%$ B 1 los_bajo_protecci $\% \mathrm{C} 3 \% \mathrm{~B} 3 \mathrm{n}$ estatal.

Children's Bureau. 2013. “The AFCARS Report \#21”. U.S. Department of Health and Human Services. http://www.acf.hhs.gov/programs/cb/resource/afcarsreport-21.

Cohen, Julie. 2009. "Infants and Toddlers in Foster Care". Zero to Three Policy Center. http://main.zerotothree.org/site/DocServer/FosterCareSingMar5. pdf?docID=7887.

Consejo Asesor Presidencial para la Reforma de las Políticas de Infancia. 2006. "El futuro de los niños es siempre hoy. Propuestas del Consejo Asesor Presidencial para la Reforma de las Políticas de Infancia”. http://www. crececontigo.gob.cl/wp-content/uploads/2009/11/Informe_del_Consejo_ Asesor_Presidencial_de_Infancia-_El_Futuro.pdf.

Consejo Nacional de la Infancia. 2015. “Caracterización de los niños de 0 a 8 años en centros residenciales. Basado en datos del Senainfo 30 de junio de 2014". Inédito.

Corporación Administrativa del Poder Judicial. 2013. "Informe estadístico de los niños/as privados de cuidado parental en Chile". Documento elaborado por el Departamento de Desarrollo Institucional de la Corporación Administrativa del Poder Judicial en el marco del proyecto "Levantamiento y unificación de la información de niños en el sistema residencial”. http://ciperchile.cl/pdfs/082013/sename/INFORME_PRESENTACION.pdf.

Dozier, Mary, Kathleen Albus, Philip Fisher \& Sandra Sepúlveda. 2002. "Interventions for Foster Parents: Implications for Developmental Theory". Development and Psychopathology 14: 843-860.

Dozier, Mary, Charles Zeanah \& Kristin Bernard. 2013. "Infants and Toddlers in Foster Care". Child Development Perspectives 7 (3): 166-171.

Fang, Xiangming, Derek Brown, Curtis Florence \& Jame Mercy. 2012. "The Economic Burden of Child Maltreatment in The United States and Implications for Prevention". Child Abuse \& Neglect 36 (2): 156-165. http:// www.sciencedirect.com/science/article/pii/S0145213411003140.

Focus. 2011. "Estudio de caracterización de colaboradoras del Sename que ejecutan proyectos de residencias de protección y el programa familias de acogida". Estudio para el Ministerio de Desarrollo Social y para el Programa de las Naciones Unidas para el Desarrollo (PNUD).

2013. "Evolución del gasto institucional del Servicio Nacional de Menores. Resumen Ejecutivo". Evaluación encargada por la Dirección de Presupuestos (Dipres). Ministerio de Hacienda. Gobierno de Chile. http://www.dipres.gob. cl/574/articles-109121_doc_pdf.pdf. 
Fundación Paz Ciudadana. 2013. "La tercera generación de políticas públicas de seguridad que Chile necesita". Fundación Paz Ciudadana. Septiembre. http://www.pazciudadana.cl/wp-content/uploads/2013/09/propuestas-pazciudadana-2014-2018.pdf.

Guzmán, Juan Andrés. 2013. “Crisis en el Sistema de Protección Sename: Informe inédito revela que $25 \%$ de los niños internados vive en 'riesgo alto"'. Centro de Investigación Periodística (Ciper). www.ciperchile.cl/2013/08/27/crisis-ensistema-de-proteccion-sename-informe-inedito-revela-que-25-de-los-ninosinternados-vive-en- $\% \mathrm{E} 2 \% 80 \% 9$ Criesgo-alto $\% \mathrm{E} 2 \% 80 \% 9 \mathrm{D}$.

James, Sigrid. 2011. "What Works in Group Care? A Structured Review of Treatment Models for Group Homes and Residential Care". Children and Youth Services Review 33 (2): 308-321. doi:10.1016/j.childyouth.2010.09.014.

Marsh, David R., Dirk Schroeder, Kirk Dearden, Jerry Sternin \& Monique Sternin. 2004. "The Power of Positive Deviance". BMJ 329: 1177-79. doi:10.1136/ bmj.329.7475.1177.

Martínez, Víctor. 2010. "Caracterización del perfil de niños, niñas y adolescentes, atendidos por los centros residenciales de Sename. Resumen ejecutivo". Unicef \& Ministerio de Justicia, Gobierno de Chile. http://www.sename.cl/ wsename/otros/resumen_SENAME_UNICEF.pdf.

_ 2011. "Análisis evaluativo del programa familia de acogida especializada de Sename". Ministerio de Justicia, Gobierno de Chile. http://www.sename.cl/ wsename/otros/estudios_2012/Informe_Final_FAE.pdf.

Mide UC. 2013. "Informe final. Un diagnóstico del sistema de cuidados alternativos del Estado de Chile. Niños, niñas y adolescentes privados de cuidado parental o en riesgo de estarlo". Estudio elaborado por MIDE UC por encargo de Aldeas Infantiles SOS. http://www.digitalmed.cl/observa/wp-content/ uploads/2013/12/INFORME_FINAL.pdf.

Ministerio de Desarrollo Social. 2012. En Chile todos contamos. Segundo catastro de personas en situación de calle. Gobierno de Chile. www. ministeriodesarrollosocial.gob.cl/plancalle/docs/En_Chile_Todos_Contamos. pdf.

Ministerio del Interior y Seguridad Pública \& Adimark GfK. 2013. "Informe final. Encuesta Nacional de Victimización por Violencia Intrafamiliar y Delitos Sexuales". Ministerio del Interior y Seguridad Pública, Gobierno de Chile. http://estudios.sernam.cl/documentos/?eMjM1MTAxOQ==Encu esta_Nacional_de_Victimizaci\%C3\%B3n_por_Violencia_Intrafamiliar_y_ Delitos_Sexuales_2012.

Muñoz, Carolina, Elaine Acosta \& Paulette Landon. 2004. "Análisis organizacional: Claves para la desinternación de la niñez institucionalizada". Revista de Trabajo Social Perspectivas 14.

National Scientific Council on the Developing Child. 2010. "The foundations of lifelong health are built in early childhood". http://developingchild.harvard. edu/resources/reports_and_working_papers/foundations-of-lifelong-health.

— 2012. "The science of neglect: The persistent absence of responsive care disrupts the developing brain". Documento de trabajo n. ${ }^{\circ} 12$. 
Nelson, Charles, Nathan Fox \& Charles Zeanah. 2014. Romania's Abandoned Children: Deprivation, Brain Development, and the Struggle ror Recovery. Cambridge, Mass: Harvard University Press.

Observa. 2014. "Caracterización de los niños, niñas y adolescentes que se encuentran en el sistema de acogimiento alternativo". www.observaderechos. $\mathrm{cl}$.

Pecora, Peter, James Whittaker, Anthony Maluccio, Richard Barth \& Diane DePanfilis. 2009. The Child Welfare Challenge: Policy, Practice, and Research. New York: Aldine Transaction.

Pritchett, Lant, Salimah Samji \& Jeffrey Hammer. 2013. "It's all about MeE: Using Structured Experiential Learning ('e') to Crawl the Design Space”. CGD Working Paper 332. Washington, DC: Center for Global Development. http:// www.cgdev.org/publication/its-all-about-mee.

Relaf, Unicef \& Sename. 2013. "Proyecto piloto para la desinstitucionalización y mejoramiento de los cuidados alternativos para niños(as) menores de 3 años en Chile". Sename, Unicef y Red Latinoamericana de Acogimiento Familiar (Relaf).

Sename. 2011. "Informe final Observatorio Nacional Programas de Familias de Acogida". Ministerio de Justicia, Gobierno de Chile. www.sename.cl/ wsename/otros/estudios_2012/Informe_final_Familias_acogida_2011.pdf.

. 2013a. "Informe consolidado evaluación acogedores. DOP. Departamento de Protección de Derechos". Ministerio de Justicia, Gobierno de Chile.

— 2013b. "Estudio familias de acogida. Encuesta: Practicando mi derecho a opinar. Opinión de niños/as en familias de acogida, sobre las condiciones de su atención”. Unidad de Estudios. Ministerio de Justicia, Gobierno de Chile.

—. 2014. "Anuario estadístico institucional 2013”. Unidad de Estudios. Ministerio de Justicia, Gobierno de Chile.

—. 2015. "Anuario estadístico institucional 2014". Unidad de Estudios. Ministerio de Justicia, Gobierno de Chile.

Shonkoff, Jack. 2000. From Neurons to Neighborhoods: The Science of Early Child Development. Washington, D.C.: National Academy Press.

Shonkoff, Jack \& Andrew Gardner. 2012. "The Lifelong Effects of Early Childhood Adversity and Toxic Stress". Pediatrics 129 (1): e231-e246.

Unicef. 2002. "Internación de niños: ¿El comienzo del fin? Crisis de los internados y transformación de las políticas de infancia en España, Italia y el Cono Sur". Publicaciones Innocenti. http://www.unicef.cl/archivos_documento/2/ internacion.pdf.

—. 2005. "Desinternación en Chile. Algunas lecciones aprendidas". Serie Reflexiones: Infancia y Adolescencia n. ${ }^{\circ}$ 4. Chile. http://www.unicef.cl/ archivos_documento/125/WORKINGPAPER4a.pdf.

—. 2012. "Cuarto estudio de maltrato infantil en Chile". Autoras: Soledad Larraín y Carolina Bascuñán. http://www.unicef.org/lac/Cuarto_estudio_ maltrato_infantil_unicef.pdf. 
- 2014. "Hidden in Plain Sight: A Statistical Analysis of Violence Against Children". Division of Data, Research and Policy. Septiembre. http://data. unicef.org/resources/hidden-in-plain-sight.

Zavala, María Isabel \& Jesús Miguel Jiménez Morago. 2014. “Una aproximación al bienestar infantil en el acogimiento familiar chileno". Revista Señales 12. Ministerio de Justicia, Gobierno de Chile.

\section{PERSONAS ENTREVISTADAS}

1. Tribunales de Familia:

-Karen Hoyuelos, jueza, Primer Juzgado de Familia de Santiago

-Constanza Feliú, jueza, Tercer Juzgado de Familia de Santiago.

2. Gobierno de Chile:

-Rolando Melo, ex director del Sename

-Hugo Herrera, jefe de gabinete de Marcela Labraña, directora del Sename

-Candy Fabio, Consejo Nacional de la Infancia

-Luis Martínez, director de estudios, Sename.

3. Implementadores de programas

-Cecilia Pacheco, directora de FAE Recoleta, Opción

-Rosario Correa, directora de Grada, centro residencial para menores

-María Inés Ross, jefa del área social, Sociedad Protectora de la Infancia

-Erasmo Morales, director de infantes y menores, Sociedad Protectora de la Infancia

-Marcela Uribe, directora de centros residenciales para infantes, Sociedad Protectora de la Infancia

-Alejandra Riveros, Aldeas SOS Chile

-Karina Farías, coordinadora de desarrollo técnico, Aldeas Infantiles SOS Chile

-Paula de la Cerda, directora Social, María Ayuda.

\section{Académicos:}

-Charles Nelson, PhD, Profesor de Pediatría del Boston Children's Hospital y Director de Investigación del Developmental Medicine Center Harvard University

-Carolina Muñoz, PhD, Departamento de Trabajo Social, Pontificia Universidad Católica

-Candice Fischer, PhD, Departamento de Psicología, Pontificia Universidad Católica

-Paula Margotta, Departamento Legal, Universidad Diego Portales

-Cecilia Casanueva, PhD, psicóloga investigadora, RTI International

-Víctor Martínez, psicólogo, Universidad de Chile. EP 